\title{
Transposed-Letter Effects in Reading: Evidence From Eye Movements and Parafoveal Preview
}

\author{
Rebecca L. Johnson \\ University of Massachusetts at Amherst
}

\author{
Manuel Perea \\ Universitat de València
}

\author{
Keith Rayner \\ University of Massachusetts at Amherst
}

\begin{abstract}
Three eye movement experiments were conducted to examine the role of letter identity and letter position during reading. Before fixating on a target word within each sentence, readers were provided with a parafoveal preview that differed in the amount of useful letter identity and letter position information it provided. In Experiments 1 and 2, previews fell into 1 of 5 conditions: (a) identical to the target word, (b) a transposition of 2 internal letters, (c) a substitution of 2 internal letters, (d) a transposition of the 2 final letters, or (e) a substitution of the 2 final letters. In Experiment 3, the authors used a further set of conditions to explore the importance of external letter positions. The findings extend previous work and demonstrate that transposed-letter effects exist in silent reading. These experiments also indicate that letter identity information can be extracted from the parafovea outside of absolute letter position from the first 5 letters of the word to the right of fixation. Finally, the results support the notion that exterior letters play important roles in visual word recognition.
\end{abstract}

Keywords: eye tracking, reading, transposed letters, parafoveal processing

How are the letter identities and letter positions within a written word encoded? Letter identity and position must both play a role or people would be unable to distinguish between anagrams such as stop, pots, tops, opts, post, and spot. Although there is general agreement that a given letter string will activate not only the appropriate word from the lexicon but also a number of perceptually similar words, the specific way in which a model specifies the coding of letter position affects which words are considered similar.

Many models, for example, assume a channel-specific (or position-specific) coding scheme. In such models, letter position is coded early in lexical processing and letters are immediately tagged to their position within the string of letters. Each letter is

Rebecca L. Johnson and Keith Rayner, Department of Psychology, University of Massachusetts at Amherst; Manuel Perea, Departamento de Metodología, Universitat de València, Valencia, Spain.

This research was conducted as part of a master's thesis by Rebecca L. Johnson under the direction of Keith Rayner. It was initiated when Manuel Perea was a sabbatical visitor at the University of Massachusetts at Amherst. The research was supported by National Institutes of Health Grant HD26765 and by Spanish Ministry of Science and Technology Grant BS02002-03286. Rebecca L. Johnson was supported as a predoctoral trainee by National Institutes of Health Grant HD07327. Manuel Perea was supported by Spanish Ministry of Education and Science Grant SEJ200505205/EDU. We thank the other members of the master's committee (Neil Berthier, Charles Clifton, and Caren Rotello) as well as Jonathan Grainger and Steve Lupker for their very helpful comments.

Correspondence concerning this article should be addressed to Rebecca L. Johnson, Department of Psychology, University of Massachusetts, Amherst, MA 01003. E-mail: becca@psych.umass.edu then processed within its specific channel independent of the other letters in the letter string. Examples of such models include the multiple read-out model (Grainger \& Jacobs, 1996), the dual-route cascaded model (Coltheart, Rastle, Perry, Ziegler, \& Langdon, 2001), the interactive activation model (McClelland \& Rumelhart, 1981), and the activation-verification model (Paap, Newsome, McDonald, \& Schvaneveldt, 1982). These models predict that the nonwords jugde, junpe, and juxxe are all equally similar to the word judge, because in each case, the nonword contains three letters in their correct letter positions. However, the nonword jugde shares all of the same letters as the word judge and differs only in a transposition of two internal, adjacent letters. So intuitively it seems that this transposed letter (TL) nonword jugde is much more similar to the base word judge than is the substituted letter (SL) nonword junpe. Indeed, research supports these intuitions; a number of experiments using a variety of tasks have found that TL nonwords are more similar to their base words than SL nonwords (i.e., the TL effect), thereby indicating that TL nonwords are able to significantly activate the lexical representation of their base word and that letter identity encoding is not channel specific (Andrews, 1996; Bruner \& O’Dowd, 1958; Chambers, 1979; Christianson, Johnson, \& Rayner, 2005; Forster, Davis, Schoknecht, \& Carter, 1987; Holmes \& Ng, 1993; O'Connor \& Forster, 1981; Perea \& Fraga, 2006; Perea \& Lupker, 2003a, 2003b, 2004a; Perea, Rosa, \& Gómez, 2005; Schoonbaert \& Grainger, 2004; Taft \& van Graan, 1998).

Perea and Lupker (2003b) conducted a series of lexical decision experiments using the masked form priming paradigm to investigate TL effects. They examined differences between TL-internal (uhser) and TL-final (ushre) nonwords in priming base words (usher) in comparison with visually similar control words in which 
the two TLs were substituted with other letters (ufner and ushno, respectively) and identity primes in which the prime and the target were identical (usher to prime usher). In comparing reaction times on targets with TL primes with those with SL primes, they found a strong effect for TL-internal primes $(30 \mathrm{~ms})$, whereas the effect for TL-final primes was relatively weak $(13 \mathrm{~ms})$ and only approached significance. Of note, the difference between the two TL conditions was only $2 \mathrm{~ms}$. The significant effect in the TL-internal condition stemmed from differences in the visually similar controls. Other experiments indicated that for TL-internal primes, priming mostly was due to the TL manipulation, but for TL-final primes, it mostly was due to the 3-4 overlapping letters that the prime shared with the base word.

Perea and Lupker (2003a) also found differences in TLinternal and TL-final effects in a masked semantic-associative priming lexical decision task. In Experiment 1, they found that although base words (judge) and TL-internal nonwords (jugde) significantly primed semantically related words (court; $14.5 \mathrm{~ms}$ and $11 \mathrm{~ms}$, respectively), nonwords created by replacing one letter of the base word (judpe) did not facilitate processing (3 $\mathrm{ms}$ ). Perea and Lupker (2003a) extended these results in Experiment 2 by comparing reaction times with targets preceded with TL-final primes (judeg to prime court) with those preceded with replacement letter primes (judpe to prime court) and were unable to find a priming effect for these TL-final nonwords. They concluded that TL-final nonwords are not effective at activating semantic information from their base words. This presumably is due to the fact that the quality of letter identity and letter position information is higher at the final letter positions than internal positions.

Although TL effects have previously been found in foveal response time tasks, the experiments reported here explored the presence of TL effects at the parafoveal level in the context of normal silent reading. Many eye movement studies have shown that readers acquire certain types of information from the parafovea (Rayner, 1998). The mere fact that readers often skip words indicates that it is possible for an entire word located in the parafovea (word $n+1$ ) to be processed while fixating on word $n$ (although this usually occurs when word $n+1$ is short, of high frequency, or highly predictable from the previous context). Even when readers do fixate on word $n+1$, however, there is still evidence that they have extracted useful information about it while fixating on word $n$ (i.e., when word $n+1$ was located in the parafovea).

Much of the research exploring the type of information extracted from the parafovea stems from studies using the eyecontingent display change technique known as the boundary paradigm (Rayner, 1975). In such experiments, a reader's eye movements are sampled every millisecond by a computer. Changes to the display are then made contingent on the reader's fixation location. In these studies (and the experiments reported here), readers are presented with a parafoveal preview of a target word that differs in some way from the target word itself. When readers' eyes cross an invisible boundary location, the preview is changed to the target word. The change occurs during a saccade (when visual input is suppressed), so readers do not consciously notice it. By comparing a number of dependent reading time measures across various parafoveal preview conditions, one can draw inferences as to the types of information gained from the parafovea.

A great deal of research in this area indicates that although purely visual (in terms of a one-to-one retinal mapping), semantic, and morphemic codes do not play a role in the parafoveal processing of words when reading English, readers do acquire partial word information (Rayner, 1998; Rayner \& Pollatsek, 1989). In order to integrate information from one fixation to the next (and therefore gain a parafoveal preview benefit), readers obtain phonological codes (Pollatsek, Lesch, Morris, \& Rayner, 1992) as well as abstract letter codes from the parafovea (McConkie \& Zola, 1979; Rayner, McConkie, \& Zola, 1980) based on visual features and orthographic rules. These abstract letter codes are then integrated with the visual information acquired when the reader fixates on the word, thereby facilitating lexical access (Rayner, 1998).

The amount of facilitation that readers receive from the parafovea, however, is a function of how far into the parafovea the preview is (Legge, Mansfield, \& Chung, 2001; Rayner et al., 1980). Using a variation of the boundary paradigm, Rayner et al. (1980) had participants look at a central fixation point and then make an eye movement to a word in the parafovea to name it. They found that each increase of $1^{\circ}$ in visual angle into the parafovea resulted in a 10-ms increase in response times. The amount and quality of information obtained from a given letter in the parafovea, then, may vary depending on its position within a letter string.

Specifically, Rayner, Well, Pollatsek, and Bertera (1982) found that reading rate did not significantly differ between conditions in which the entire word to the right of fixation or only the first three letters of the next word were present in the parafovea as long as the remaining letters were replaced with visually similar letters. Their study used a continual display change technique, known as the moving window paradigm (McConkie \& Rayner, 1975), in which the parafoveal preview condition held for each fixation, rather than just for a given target word. They concluded that preserving the first three letters of the word to the right of fixation was sufficient to elicit normal reading rates and that "visual information extracted from the end of the word to the right of fixation either may not be very precise or may not be used very frequently" (p. 547). Inhoff (1989a), however, found that readers extract useful parafoveal information from word-final letters. Although preview benefit was greatest when readers were presented with the entire word to the right of fixation, having either the beginning three letters or the final three letters of the word also facilitated reading when compared with no preview at all (see also Briihl \& Inhoff, 1995). Therefore, we cannot totally discount the usefulness of parafoveal information from letters beyond the first three letters of the word to the right of fixation.

The fact that normal silent reading involves the movement of the eyes (and therefore the integration of information across saccades) and places the preview of the target word (or the prime word) to the right of fixation (where the final letters of the word to the right fall further from the center of fixation than the internal letters) opens up the possibility that the pattern of findings in the experiments reported here will differ from those of TL naming and lexical decision studies. In other words, TL effects may differ (or even fail to exist) when studied in a more natural reading environment. 


\section{Experiment 1}

The three current eye movement experiments were carried out to explore the role of parafoveal letter identity and letter position within the context of normal silent reading. In Experiment 1, Perea and Lupker's (2003b) target words were embedded in sentences to examine TL effects during reading. By varying the parafoveal preview conditions that readers receive before fixating on the target word, we can determine what type of information they extract from the parafovea. If readers are able to extract complete (or even partial) letter identity from the parafovea outside of absolute letter position ${ }^{1}$ and then integrate those abstract letter codes with information from the next fixation (when the word appears in the fovea), there should be a preview benefit for TL preview conditions (uhser and ushre) when compared with SL preview conditions (ufner and ushno). In fact, if letter position is not extracted at all from the parafovea, there should be no difference between TL preview conditions and an identity condition (in which usher is the parafoveal preview of usher), because in each case, the preview provides correct letter identity information for all five letters. However, if parafoveal information about letter identity is dependent on absolute letter position, there should be no difference between the TL and SL preview conditions, because in both cases, only three of the five letters within the letter string are correct. Finally, by varying the positions at which the manipulations occurred, we can explore the importance of specific letter positions in parafoveal letter encoding.

\section{Method}

Participants. Thirty members of the University of Massachusetts at Amherst community participated in the experiment. They either received course credit or monetary compensation $(\$ 5-\$ 8)$ for their time. All participants had normal vision or soft contacts and were native speakers of American English. They were all naive to the purpose of the experiment.

Apparatus. Participants were seated $61 \mathrm{~cm}$ from a 15-in. NEC MultiSync 4FG color monitor in which single-line sentences were presented for them to read in Borland $\mathrm{C}$ font. At this distance, 3.8 letters equaled $1^{\circ}$ of visual angle. Eye movements were recorded using a Fourward Technologies (Buena Vista, VA) Dual Purkinje Eyetracker (Generation VI) interfaced with a Pentium computer. This eyetracker has a spatial resolution of 10 min of arc. Although reading took place binocularly, eye movements were recorded only from the participant's right eye, with eye position sampled every millisecond.

Stimuli. The 120 five-letter words used by Perea and Lupker (2003b) were used as target words and embedded into a single-line sentence with no more than 74 characters. Target words never occupied the sentence-initial or sentence-final word position. The Francis and Kučera (1982) frequency count was used to estimate target word frequencies. Frequencies ranged from 1 per million written words to 694 per million $(M=88)$ and represented a variety of word classes.

Five parafoveal preview conditions were generated for each target word, again based on Perea and Lupker (2003b). In the identity condition, the preview was identical to the target word (clerk as the preview of clerk). The TL-internal condition involved a transposition of two internal and adjacent letters (celrk as the preview of clerk). The SL-internal condition involved a substitution of two internal and adjacent letters (cohrk as the preview of clerk). The TL-final condition involved a transposition of the two final letters (clekr as the preview of clerk). The SL-final condition involved a substitution of the two final letters (clefn as the preview of clerk). In the two substitution conditions, the letters substituted were visually similar to the two TLs in their respective comparison condition (i.e., the TL-internal and SL-internal conditions were visually similar to one another as were the TL-final and the SL-final conditions). Ascending letters ( $b, d, f, h, k, l$, and $t$ ) were substituted with ascending letters, descending letters $(g, j, p, q$, and $y$ ) were substituted with descending letters, and letters that neither ascend nor descend were substituted with visually similar letters. Vowels were substituted with vowels and consonants were substituted with consonants. In the TL- and SL-internal conditions, manipulations occurred at either the second and third or at the third and fourth letter positions.

Design and procedure. After reading a brief description of the experimental procedure, participants were verbally instructed about the task. In order to minimize head movements during the experiment, we prepared a bite bar for each participant, and we appropriately adjusted a forehead rest. The initial calibration procedure then took place and lasted approximately $5 \mathrm{~min}$. After calibration, participants read eight practice sentences (all five experimental conditions were represented) to familiarize themselves with the procedure.

The experimental sentences then followed, presented in random order. Sentences were presented one at a time on the center row of the monitor, and the boundary paradigm (Rayner, 1975) was used to vary parafoveal preview information (see Figure 1 for an example). When a sentence was initially presented on the monitor, the participant was fixating on the first letter of the first word in the sentence and the target word was replaced with one of the preview conditions. Once the participant's eyes crossed an invisible boundary just to the left of the space immediately preceding the target word, the preview changed to the target word. Because this display change occurred while the participant's eyes were moving, participants did not notice any change. The target word then remained present until the participant indicated that he or she was finished reading the sentence. Participants were told to read each sentence silently at a comfortable pace and to press a button on a response box when they finished reading the sentence. The accuracy of the initial calibration was then confirmed and the process repeated with the presentation of another sentence initiated by the experimenter. Each participant read each sentence only once, with one of the five preview conditions. Counterbalancing procedures ensured that every participant read 24 sentences in each of the 5 preview conditions. There were 6 participants in each counterbalancing condition. To ensure that participants were in fact reading for comprehension and not merely skimming the sentences, we presented questions after $10 \%$ of the trials. Participants were instructed to read the question and the 2 possible answers and to then select the correct choice by pressing the corresponding button on their response box. Comprehension scores ranged from $80 \%$ to $100 \%$, with a mean of $96 \%$. The entire procedure took less than $45 \mathrm{~min}$.

Normative data. Previous research has found that highly predictable words are skipped or fixated for shorter durations than unpredictable words (Rayner, 1998). In order to increase the likelihood that target words would be fixated (thereby providing a measure of processing time as a function of parafoveal preview), we wrote sentences in such a way that the target words were not predictable from their previous context. Before running Experiment 1, we normed the experimental sentences for predictability. In the predictability task, 10 participants were given the first part of the experimental sentence (up to the target word) and then asked to predict the next word in the sentence (i.e., predict the target word). The mean predictability score across the items was less than $1 \%$, indicating that items were not at all predictable from their preceding contexts.

In addition, experimental sentences were normed for understandability to ensure that the target word in each sentence fit well within the context of that sentence. Ten participants were asked to judge on a scale from 1 (not understandable) to 7 (very understandable) how well each target word fit into the given sentence. All target words were rated as understandable

${ }^{1}$ The phrase letter position here and throughout the discussion of these three experiments refers to absolute, length-dependent letter-position, as opposed to a more loose definition such as relative letter position. 
within the sentence $(M=6.27)$. None of the participants in either of the two norming procedures took part in the eyetracking portion of the experiment. The experimental sentences and preview conditions are in Appendix A.

\section{Results}

The amount of time spent fixating on the target word is thought to reflect processing time for that word (Rayner, 1998; Rayner \& Pollatsek, 1989). Furthermore, when readers obtain a useful parafoveal preview of a word, it lessens the processing time on the word when it is directly fixated, resulting in shorter fixation durations. Thus, by examining how the fixation durations on target words vary as a function of the parafoveal preview, we can infer the amount of useful information the reader obtains from the parafovea. There are, however, a number of ways to calculate the amount of time spent on the target word. These include first fixation duration, single fixation duration, and gaze duration. First fixation duration is the amount of time a reader spends on the initial fixation on the target word; if a reader fixates on the target word more than once (i.e., refixates on the target word before leaving the word or regresses back to the target word after leaving it), only the initial duration is considered. Single fixation duration represents those fixations for which the reader made one and only one fixation on the target word on the first pass. This, then, eliminates trials in which the reader refixated the target word before leaving it. Finally, gaze duration represents the sum of fixation durations on a target word before the reader leaves that word.

Trials in which the display change triggered too early, the eyetracker lost track of the eye, or in which the participant blinked on the pretarget word, target word, or posttarget word were all discarded. Consistent with most eye movement research (Rayner,

\footnotetext{
The voters argued that they deserve loewr taxes and better schools.

The voters argued that they deserve loewr taxes and better schools.

The voters argued that they deserve loewr taxes and better schools.

The voters argued that they deserve loewr taxes and better schools.

The voters argued that they deserve loewr taxes and better schools.

The voters argued that they deserve lower taxes and better schools.

The voters argued that they deserve lower taxes and better schools.
}

The voters argued that they deserve lower taxes and better schools.

The voters argued that they deserve lower taxes and better schools.

Figure 1. Example sentence using the boundary paradigm. The target word, although indicated above in boldface, was not presented in boldface in the present three experiments. The asterisk below each sentence indicates the reader's fixation location. When the reader's eye crosses the boundary (located just to the left of the space preceding the target word), the parafoveal preview changes to the target word. In the example above, a transposed-letter-internal manipulation serves as the parafoveal preview.
Table 1

Means as a Function of Type of Manipulation and Manipulation Location for Experiment 1

\begin{tabular}{lccc}
\hline $\begin{array}{c}\text { Parafoveal } \\
\text { preview } \\
\text { condition }\end{array}$ & $\begin{array}{c}\text { First } \\
\text { fixation }\end{array}$ & $\begin{array}{c}\text { Single } \\
\text { fixation }\end{array}$ & $\begin{array}{c}\text { Gaze } \\
\text { duration }\end{array}$ \\
\hline Identity baseline & 264 & 270 & 278 \\
TL, internal & 272 & 276 & 300 \\
SL, internal & 283 & 292 & 308 \\
TL, final & 273 & 282 & 301 \\
SL, final & 287 & 292 & 317 \\
\hline
\end{tabular}

Note. All durations are in milliseconds. $\mathrm{TL}=$ transposed letter; $\mathrm{SL}=$ substituted letter.

1998), trials in which there were two fixations on adjacent letters and one of the fixations was short (less than $120 \mathrm{~ms}$ ) were pooled. In addition, extremely short $(<120 \mathrm{~ms})$ isolated fixations and extremely long $(>600 \mathrm{~ms}$ ) fixations were eliminated from the data prior to analyses. Altogether, $31 \%$ of the data were eliminated. ${ }^{2}$ The mean first fixation duration, single fixation duration, and gaze duration for each of the five parafoveal preview conditions are shown in Table 1 .

The four nonidentity conditions were analyzed by a 2 (type of manipulation: TL or SL) $\times 2$ (letter manipulation position: internal or final) analysis of variance (ANOVA). Error variance was calculated over participants $\left(F_{1}\right)$ and over items $\left(F_{2}\right)$. Because all participants were presented with 24 items in each of the 5 preview conditions and each item was presented in each one of the 5 preview conditions across the 5 counterbalancing conditions, both factors were within participants and within items. The main effect of letter manipulation type was significant both by participants and by items on all viewing duration measures. There was a $13-\mathrm{ms}$ effect for first fixation duration, $F_{1}(1,29)=6.836, p<.05$, and $F_{2}(1,117)=7.885, p<.01$, a 13-ms effect for single fixation duration, $F_{1}(1,29)=9.192$, $p<.01$, and $F_{2}(1,110)=6.318, p<.05$, and a $12-\mathrm{ms}$ effect for gaze duration, $F_{1}(1,29)=6.559, p<.05$, and $F_{2}(1,117)=$ $5.658, p<.05$. In each case, previews involving a transposition of 2 letters resulted in shorter viewing durations than previews involving a substitution of 2 letters. The main effect of letter manipulation position, however, did not reach significance on any of these target fixation durations either by participants (all $p \mathrm{~s}>.30$ ) or by items (all $p \mathrm{~s}>.43$ ). The interaction between letter manipulation type and letter manipulation position was also not significant on any viewing duration measure either by participants (all $p \mathrm{~s}>.27$ ) or by items (all $p \mathrm{~s}>.34$ ). Therefore, the TL condition provided a preview benefit compared with its visually similar control when the manipulation fell either in the middle or at the end of the word.

\footnotetext{
${ }^{2}$ This seemingly high data elimination rate primarily was due to a large number of instances in which the display change triggered too early. It should be noted, though, that each participant contributed at least 10 data points to each of the 5 conditions. To lower the data elimination rate for Experiments 2 and 3, we used a Generation V Fourward Technologies Dual Purkinje Eyetracker, which is less sensitive to small adjustive eye movements that can cause early display changes.
} 
Further analyses compared the identity condition with each of the two TL preview conditions. For first fixation duration, there was an 8 -ms difference between the identity condition and the TL-internal condition that was significant by participants, $t_{1}(29)=$ $2.353, p<.05$, but not by items, $t_{2}(119)=0.869, p=.19$. The 6-ms difference between these two conditions in single fixation duration was only marginally significant by participants, $t_{1}(29)=$ $1.448, p=.079$, and by items, $t_{2}(118)=1.407, p=.081$. For gaze duration, the 22-ms difference was significant, $t_{1}(29)=3.605, p<$ .001 , and $t_{2}(119)=2.639, p<.01$.

Comparison of the identity condition with the TL-final condition yielded a similar pattern of effects. For first fixation duration, the 9-ms difference was significant by participants, $t_{1}(29)=1.977$, $p<.05$, but not by items, $t_{2}(118)=0.668, p=.253$. The $12-\mathrm{ms}$ difference in single fixation duration was also significant by participants, $t_{1}(29)=2.612, p<.01$, but only marginally significant by items, $t_{2}(117)=1.502, p=.068$. Finally, just as in the comparison between the gaze durations from the identity condition and the TL-internal condition, the 23-ms difference between the identity condition and the TL-final condition was significant both by participants, $t_{1}(29)=3.949, p<.001$, and by items, $t_{2}(118)=$ $2.831, p<.01$.

Finally, in a third contrast, the identity condition was compared with the mean of the two final manipulation conditions (i.e., the TL-final and the SL-final conditions). If letter identity information is not extracted by the reader any further than three letter positions of the word to the right of fixation, as Rayner et al. (1982) claimed, there should be no difference among these three conditions. In each case, the first three letters of the parafoveal preview are correct and in their correct letter position. Any difference between the identity condition and these two final manipulation conditions, then, would indicate that readers are extracting useful letter identity and letter position information from further into the parafovea than just three letters. In fact, this contrast was significant across participants and items for all three viewing duration measures. The identity condition yielded fixation times $16 \mathrm{~ms}$ shorter than the final conditions for first fixation duration, $t_{1}(29)=3.832, p<$ .001 , and $t_{2}(118)=2.309, p=.05,17 \mathrm{~ms}$ shorter for single fixation duration, $t_{1}(29)=3.772, p<.001$, and $t_{2}(115)=3.118$, $p<.01$, and $31 \mathrm{~ms}$ shorter for gaze duration, $t_{1}(29)=5.744, p<$ .001 , and $t_{2}(118)=4.934, p<.001$.

\section{Discussion}

The results from Experiment 1 indicate that TL effects that have been found in naming and lexical decision experiments also exist during normal silent reading. This is evidenced by the fact that across all three viewing duration measures (first fixation duration, single fixation duration, and gaze duration), parafoveal previews that consisted of a transposition of two adjacent letters provided greater facilitation than previews that consisted of a substitution of two adjacent letters. This poses a challenge to models of visual word recognition that assume a channel-specific coding scheme to letter processing. These models assert that letters are first tagged to their specific channel within the letter string and then encoded within that specific channel. Thus, they predict that both the TL and SL nonwords should provide equal parafoveal preview benefit, because in both cases, three of the five letters are in their correct letter position. ${ }^{3}$
The fact that TL preview conditions led to shorter viewing durations than SL preview conditions indicates that letter identity information can be extracted parafoveally outside of absolute letter position. This extends findings from response time tasks that have shown this independence between letter identity and absolute letter position when all information (prime, mask, and target) is presented foveally. However, in most analyses, the identity condition provided the greatest preview benefit. If letter positions were not encoded at all in the parafovea, the identity and the TL preview conditions should provide equal parafoveal benefit, because in each case, all of the correct letters are present. That this was not the case indicates that correct letter position does play a significant role in facilitating preview benefit. So, although letter identity can be extracted outside of absolute letter position in the parafovea, correct letter position does facilitate word retrieval processes.

Although there was a significant effect of letter manipulation type, there were no differences due to the location of the transposition or substitution. TL nonwords led to shorter viewing times than SL nonwords in both internal and final manipulations. These results differ from those of Perea and Lupker (2003b), who found that although internal transpositions (jugde) led to faster lexical decision times than internal substitutions (jupte), the difference between final manipulations was less pronounced. In other words, the TL effect was stronger for internal manipulations than for final manipulations. Nonetheless, we should note that the main difference in the results of these two studies is that of the SL-internal condition: In Perea and Lupker's (2003b) masked form priming experiment, the two TL conditions differed by only $2 \mathrm{~ms}$. The difference in priming effects as a function of manipulation position was due to the increased response times for the SL-internal condition. A temptative explanation for this discrepancy is the prime location across the two experiments. Although participants in Perea and Lupker's (2003b) study were fixating directly at the prime, and more specifically at the internal letter positions, letter identification at these positions is much more likely than when these letters are positioned in the parafovea (where acuity is limited), to the right of fixation. For the SL-internal condition in Perea and Lupker's (2003b) study, then, participants were extracting incorrect letters from the prime (i.e., letters not used in the target word) and this was likely to inhibit word recognition processes. For instance, with foveal presentations in a lexical decision task, nonwords created by transposing two letter positions are perceptually more similar to their base words than the nonwords

\footnotetext{
${ }^{3}$ Another problem that these channel-specific models have is that they assume that the lexical selection processes for words of differing lengths are independent of one another. Thus, according to these models, a fourletter word such as hose would be unable to prime the lexical representation of a five-letter word such as house, when in fact such priming effects are robust (De Moor \& Brysbaert, 2000; Humphreys et al., 1990; Perea \& Carreiras, 1998; Peressotti \& Grainger, 1999; Schoonbaert \& Grainger, 2004). Both the MROM-p model (Jacobs, Rey, Ziegler, \& Grainger, 1998) and the dual-route cascaded model (Coltheart et al., 2001), which encode letter identities in terms of their relative letter positions, are able to account for these findings but are still unable to explain TL effects.
} 
Table 2

Means as a Function of Type of Manipulation, Manipulation Location, and Parafoveal Word Shape for the Replication Study of Experiment 1

\begin{tabular}{|c|c|c|c|}
\hline $\begin{array}{c}\text { Parafoveal } \\
\text { preview } \\
\text { condition }\end{array}$ & $\begin{array}{c}\text { First } \\
\text { fixation }\end{array}$ & $\begin{array}{c}\text { Single } \\
\text { fixation }\end{array}$ & $\begin{array}{c}\text { Gaze } \\
\text { duration }\end{array}$ \\
\hline \multicolumn{4}{|c|}{ Congruent parafoveal word shape } \\
\hline Identity baseline & 286 & 292 & 298 \\
\hline TL, internal & 290 & 292 & 303 \\
\hline SL, internal & 298 & 306 & 317 \\
\hline TL, final & 296 & 300 & 309 \\
\hline SL, final & 303 & 311 & 323 \\
\hline \multicolumn{4}{|c|}{ Incongruent parafoveal word shape } \\
\hline Identity baseline & 278 & 284 & 290 \\
\hline TL, internal & 290 & 292 & 305 \\
\hline SL, internal & 301 & 307 & 318 \\
\hline TL, final & 294 & 297 & 309 \\
\hline SL, final & 294 & 303 & 317 \\
\hline
\end{tabular}

Note. All durations are in milliseconds. TL $=$ transposed letter; SL $=$ substituted letter.

created by substituting just one letter, and they produce a greater "pseudoword" frequency effect (see Perea et al., 2005). ${ }^{4}$

Another interesting finding is that the identity condition led to shorter viewing durations than the mean of the two final manipulation conditions (TL final and SL final). According to Rayner et al. (1982), readers do not extract useful letter identity information from more than the first three letters of the word to the right of fixation. On the basis of this conclusion, one would predict that the identity condition, the TL-final condition, and the SL-final condition would be equally facilitative as a parafoveal preview of the base word. That is, in each case, the first three letters of the target word (in their correct letter positions) are available to the reader before fixation. Thus, if readers only extract letter identity information from the first three letters of the word to the right of fixation, there should be no differences across these three conditions. Yet, the identity condition provided more facilitation than the TL-final condition and, likewise, the TL-final condition provided significantly more facilitation than the SL-final condition. This argues that readers are able to extract both letter identity and letter position information from the parafovea out to at least five letter positions of the word to the right of fixation.

Bear in mind that overall word shape can offer supplemental information to letter-based orthographic processing (Perea \& Rosa, 2002) and, indeed, reading times may depend on whether the letters in the parafovea are visually similar to the letters in the target item (Inhoff, 1989b; McConkie \& Rayner, 1975; Rayner et al., 1980, 1982). A follow-up study to Experiment 1 was run to explore the potential interaction between TL effects and word shape. Forty-five members of the same participant pool as in Experiment 1 read sentences containing the same five preview conditions as in Experiment 1, with the additional factor of word shape. Half of the five-letter target words (60 items) provided a visually similar parafoveal preview after both an internal manipulation and a final manipulation (crown, corwn, cronw), whereas half provided a visually dissimilar parafoveal preview (clerk, celrk, clekr). The two target word groups were matched for fre- quency, bigram frequency, predictability, and understandability. The same boundary paradigm and counterbalancing procedures used in Experiment 1 were used. The results from the ANOVA and contrasts replicated all of the findings from Experiment 1. Of critical importance, the main effect of word shape was not significant, nor were any interactions involving shape $(p s>.19)$, indicating that letter identity can be extracted from the parafovea outside of absolute letter position even when parafoveal word shape is incorrect (see Table 2 for the mean first fixation duration, single fixation duration, and gaze duration for each of the 10 parafoveal preview conditions).

\section{Experiment 2}

The fact that a TL effect was observed when the TL-final condition was compared with the SL-final condition indicates that readers are able to extract letter identity information from at least the first five letters of the word to the right of fixation. Experiment 1 by itself does not address the limitations of letter identity extraction because only five-letter words were used as target stimuli. Longer words, however, allow us to examine letter identity effects as a function of their distance from the fovea because they include letters that span even further into the parafovea. Using longer words also allows us to test whether TL effects are greater in longer words than in shorter words, as previous research suggests (Davis \& Andrews, 2001; Perea \& Lupker, 2003b). Thus, Experiment 2 used seven-letter words as target stimuli. The same five parafoveal preview conditions used in Experiment 1 were

\footnotetext{
${ }^{4}$ The exact degree to which correct letters facilitate processing and incorrect letters inhibit processing is unknown, although it is likely that both processes are at work in visual word recognition. In the current experiments, an identity control was used as a baseline to measure processing. However, the use of other control baselines (e.g., a series of $X \mathrm{~s}$ ) in future research may help to address this question.
} 
again used, although internal manipulations fell between the fourth and fifth letters of the seven-letter words.

If readers are able to successfully extract letter identity information from beyond the fifth letter of the word to the right of fixation (outside of absolute letter position), we should expect to again see TL effects at both the internal and final manipulation locations of these seven-letter words. On the other hand, if readers are unable to extract letter identity information from more than five letters of the word to the right of fixation (outside of absolute letter position), there should be no difference between the TL-final and SL-final conditions. Furthermore, there should also be no difference between these two conditions and the identity condition.

\section{Method}

Participants. Thirty-five members of the University of Massachusetts at Amherst community participated in the experiment. They all received either course credit or monetary compensation $(\$ 5-\$ 8)$ for their time. All participants had normal vision or soft contacts and were native speakers of American English. Finally, all participants were naive to the purpose of the experiment.

Apparatus. The apparatus was the same as in Experiment 1, except a Generation V Fourward Technologies Dual Purkinje Eyetracker was used.

Stimuli. Sixty target words, all seven-letters in length, were used as stimuli. Each word was embedded into a single-line sentence containing no more than 77 letters. Target words never occupied the sentence-initial or sentence-final word position. The Francis and Kučera (1982) frequency count was used to estimate target word frequencies. Frequencies ranged from 1 per million to 222 per million $(M=49)$ and again represented a variety of word classes. The five parafoveal preview conditions used in Experiment 1 were generated for each target word. Previews (a) were identical to the target word (acrobat as the preview of acrobat), (b) involved a transposition of two internal and adjacent letters (acrboat as the preview of acrobat), (c) involved a substitution of two internal and adjacent letters (acrdeat as the preview of acrobat), (d) involved a transposition of the two final letters (acrobta as the preview of acrobat), or (e) involved a substitution of the two final letters (acrobko as the preview of acrobat). Internal manipulations always involved the fourth and fifth letters in the seven-letter word, and final manipulations always involved the sixth and seventh letters, allowing us to address the limitations of letter identity extraction from the parafovea, given the results from Experiment 1. The same boundary paradigm and counterbalancing procedures used in Experiment 1 were used in Experiment 2. Each participant read 12 sentences in each of the five preview conditions.

Design and procedure. The design and procedure were the same as that in Experiment 1. Comprehension questions occurred after $15 \%$ of the trials; accuracy ranged from $89 \%$ to $100 \%(M=94 \%)$.

Normative data. Before running Experiment 2, we normed experimental sentences for both predictability and understandability (using the same procedures described in Experiment 1). The overall mean predictability score was again less than $1 \%$, indicating that the target words were not predictable from the previous context. In addition, all target words were rated as understandable within the sentence $(M=6.43)$. None of the participants in either norming procedure (10 in each) participated in the eyetracking portion of the experiment. The experimental sentences and preview conditions are in Appendix B.

\section{Results}

As in Experiment 1, trials in which the display change triggered too early, the eyetracker lost track of the reader, or the participant blinked on the pretarget word, target word, or posttarget word were all discarded. Again, short fixations were combined with fixations on an adjacent letter. Extremely short isolated fixations ( $<120 \mathrm{~ms})$ and extremely long fixations (>600 ms) were eliminated from the data prior to analyses. These trimming procedures resulted in the elimination of $16 \%$ of the data. The mean first fixation duration, single fixation duration, and gaze duration for each of the five parafoveal preview conditions can be found in Table 3 .

The four nonidentity conditions were analyzed by a 2 (type of manipulation: transposition or substitution) $\times 2$ (manipulation location: internal or final) ANOVA. As in Experiment 1, type of manipulation and manipulation location were within-participants and within-items factors. There was a significant main effect of manipulation type across all viewing duration measures. For first fixation duration, there was a 9-ms effect, $F_{1}(1,34)=4.53, p<$ .05 , and $F_{2}(1,59)=8.532, p<.01$; for single fixation duration, there was an 11 -ms effect, $F_{1}(1,34)=5.987, p<.05$, and $F_{2}(1$, $58)=6.999, p<.05$; and for gaze duration, there was a $16-\mathrm{ms}$ effect, $F_{1}(1,34)=7.44, p<.05$, and $F_{2}(1,59)=11.696, p<.01$. In each case, the viewing duration of the target word was significantly shorter when the target was preceded with a TL preview than an SL preview. Also similar to Experiment 1, the main effect of manipulation location did not reach significance on any viewing duration measure by participants (all $p \mathrm{~s}>.43$ ) or by items (all $p \mathrm{~s}>.55)$.

However, unlike the previous experiment, there was a significant interaction between type of manipulation and manipulation location. This interaction was significant across all viewing duration measures in the participant analyses (first fixation duration, $F_{1}[1,34]=5.049, p<.05$; single fixation duration, $F_{1}[1,34]=$ $4.385, p<.05$; gaze duration, $\left.F_{1}[1,34]=5.295, p<.05\right)$ and at least marginally significant by items (first fixation duration, $F_{2}[1$, $59]=5.703, p<.05$; single fixation duration, $F_{2}[1,58]=3.234$ $p=.077$; gaze duration, $\left.F_{2}[1,59]=3.546, p=.065\right)$. In each case, the interaction was a result of stronger TL effects for internal than for final manipulations. Although the TL-internal condition was $19 \mathrm{~ms}$ shorter than the SL-internal condition for first fixation duration, the TL-final condition was actually $1 \mathrm{~ms}$ longer than the SL-final condition. Likewise, the TL effects for the internal manipulation position were $20 \mathrm{~ms}$ and $28 \mathrm{~ms}$ for single fixation duration and gaze duration, respectively, whereas the TL effects

Table 3

Means as a Function of Type of Manipulation and Manipulation Location for Experiment 2

\begin{tabular}{lccc}
\hline $\begin{array}{c}\text { Parafoveal } \\
\text { preview } \\
\text { condition }\end{array}$ & $\begin{array}{c}\text { First } \\
\text { fixation }\end{array}$ & $\begin{array}{c}\text { Single } \\
\text { fixation }\end{array}$ & $\begin{array}{c}\text { Gaze } \\
\text { duration }\end{array}$ \\
\hline Identity baseline & 282 & 287 & 307 \\
TL, internal & 288 & 295 & 316 \\
SL, internal & 307 & 315 & 344 \\
TL, final & 301 & 308 & 329 \\
SL, final & 300 & 309 & 333 \\
\hline
\end{tabular}

Note. All durations are in milliseconds. $\mathrm{TL}=$ transposed letter; $\mathrm{SL}=$ substituted letter. 
for the final manipulation position were only $1 \mathrm{~ms}$ and $4 \mathrm{~ms}$, respectively. ${ }^{5}$

In addition, the identity condition was compared with each of the two TL preview conditions. As in Experiment 1, the identity condition led to significantly shorter viewing durations than the TL-final condition. This effect was $19 \mathrm{~ms}$ for first fixation duration, $t_{1}(34)=3.259, p<.01$, and $t_{2}(59)=3.507, p<.001,21 \mathrm{~ms}$ for single fixation duration, $t_{1}(34)=3.864, p<.001$, and $t_{2}(59)=$ $3.515, p<.001$, and $22 \mathrm{~ms}$ for gaze duration, $t_{1}(34)=3.155, p<$ .01 , and $t_{2}(59)=2.424, p<.01$. However, unlike Experiment 1 , the identity condition led to significantly shorter viewing durations when compared with the TL-internal condition only for single fixation duration in which the 8-ms effect was marginally significant by participants, $t_{1}(34)=1.393, p=.086$, and significant by items, $t_{2}(58)=1.688, p<.05$. The 6 -ms difference for first fixation duration and the 9-ms difference for gaze duration were not significant by participants (all $p$ s $>.107$ ) or by items (all $p \mathrm{~s}>$ .154). This difference in results from Experiment 1 to Experiment 2 suggests that TL effects are stronger for longer words than for shorter words; at least for TL-internal manipulations, TL nonwords are more similar to their base words in longer words than in shorter words.

A contrast comparing fixation times in the identity condition with the mean of those from the two final manipulation conditions revealed a highly significant difference. The identity condition was $19 \mathrm{~ms}$ shorter in first fixation duration, $t_{1}(34)=3.793, p<.001$, and $t_{2}(59)=4.055, p<.001,22 \mathrm{~ms}$ shorter in single fixation duration, $t_{1}(34)=4.241, p<.001$, and $t_{2}(59)=4.561, p<.001$, and $24 \mathrm{~ms}$ shorter in gaze duration, $t_{1}(34)=4.27, p<.001$, and $t_{2}(59)=3.433, p<.001$.

\section{Discussion}

As in Experiment 1, the main effect of letter manipulation type was significant across all viewing duration measures. Previews containing a transposition of two adjacent letters provided greater preview benefit than previews containing a substitution of two adjacent letters. These results further support the notion that TL effects do exist in silent reading and are not only found in short five-letter words but also in longer seven-letter words. These TL effects indicate that letter identity information can be extracted outside of absolute letter position parafoveally. Also consistent with Experiment 1, there was no main effect of letter position. However, unlike Experiment 1, there was an interaction between letter manipulation type and manipulation location. This interaction revealed that the TL effect was stronger for internal manipulations than for final manipulations. When the letter manipulation took place at the fourth and fifth letter position (internal manipulation), transpositions led to shorter viewing durations than their respective substitution nonword controls. In contrast, this effect was absent when the letter manipulation took place at the sixth and seventh letter position (final manipulation).

That the TL effect still held for internal manipulations indicates that readers are able to successfully extract letter identity information from up to the fifth letter of the word to the right of fixation outside of absolute letter position. However, the significant interaction suggests that readers are unable to extract letter identity information from further than five letters of the word to the right of fixation outside of absolute letter position. Whether readers are able to extract letter identity information from this extended region dependent on letter position is partially addressed by analyzing the relationship of the identity condition to the mean of the two final manipulation conditions. As noted earlier, if readers are unable to gain any useful letter identity information from the letters beyond the first five letters of the word to the right of fixation, there should not only be no difference between the TL-final and SL-final conditions but also no difference between these two conditions and the identity condition. Although the data were consistent with this conclusion on the former analysis, the latter analysis revealed a significant difference between conditions. That is, although the first five letters of the identity condition, the TL-final condition, and the SL-final condition were all correct and in their correct letter position, the identity condition led to significantly shorter viewing durations than these other two conditions. This finding suggests that readers are able to extract letter identity information from beyond this five-letter region, perhaps through gaining useful information from the word-final letter in the letter string.

The comparison between the identity condition and the two TL conditions indicates two things. First, the fact that the identity condition led to significantly shorter viewing durations than the TL-final condition indicates that correct letter position does play a significant role in reading. Just as in Experiment 1, then, letter identity can be extracted outside of absolute letter position in the parafovea, but correct letter position facilitates word retrieval processes. Second, although the identity condition led to shorter viewing durations than the TL-final condition, it was not significantly different from the TL-internal condition, even though in each of these two TL conditions, five out of the seven letters in the target word were in their correct location. The fact that the identity condition led to significantly shorter viewing times than the TLfinal manipulation but not the TL-internal manipulation suggests that letter position may be anchored by the word-final letter.

Although many foveal tasks have found that both the wordinitial and word-final letters of a word play a major role in word recognition (Friedmann \& Gvion, 2001; Humphreys, Evett, \& Quinlan, 1990; Jordan, 1990; McCusker, Gough, \& Bias, 1981; Perea, 1998), the arguments for and against the privileged role of word-final letters within normal silent reading tasks are mixed, as are the data supporting each claim. On the one hand, word-final letters may play a significant role in word recognition (even at the

\footnotetext{
${ }^{5}$ It may be important to note that there might be some differences between consonant transpositions and vowel transpositions (Perea \& Lupker, 2004a, 2004b). In a recent masked priming study (Perea \& Lupker, 2004b) with English stimuli, form priming effects of a similar magnitude were obtained for consonant transpositions (e.g., hosre-HORSE vs. honceHORSE) and for consonant-vowel transpositions (brcik-BRICK vs. brsok$B R I C K)$, whereas there were no priming effects for vowel transpositions (draem-DREAM vs. droim-DREAM). In other words, as long as the transposition involved a consonant, TL primes were much more effective than SL primes, but when the transposition involved two vowels, there was no difference. In the current study in which the TL effect was different for internal versus final manipulations, the percentage of vowel-vowel transpositions was quite similar across manipulation locations (2\% vs. $0 \%$, respectively) indicating that our findings are not driven by this potential factor. Furthermore, further research (Johnson, in press) suggests that there are no differences in vowel and consonant processing at the parafoveal level.
} 
parafoveal level) because they are less susceptible to effects of lateral masking (Humphreys et al., 1990; Jordan, Thomas, Patching, \& Scott-Brown, 2003). On the other hand, the amount of information readers can process in the parafovea is a function of the distance from the point of fixation (Legge et al., 2001; Rayner et al., 1980) because letters placed further from the fovea (as is the case with word-final letters in the parafovea) are viewed with less detail as a result of the physical characteristics of the retina, which provide lower visual acuity further into the parafovea. Although some have found that the initial bigram provides more facilitation than the exterior letter pair (Briihl \& Inhoff, 1995; Rayner et al., 1980), others have found the opposite to be true (Jordan et al., 2003).

\section{Experiment 3}

We have argued that the absence of TL effects at the word-final position in seven-letter words (that are present in five-letter words) is due to the eccentricity of the word-final letters in these longer words. That is, although readers are able to extract letter identity information outside of absolute letter position out to five letter positions of the word to the right of fixation, they are not able to do so beyond this point. Furthermore, we have claimed that the shorter viewing durations following the identity preview compared with those following the TL-final and the SL-final conditions are due to the privileged role of the word-final letter in word recognition. In order to further test this interpretation of the results from the first two experiments, we ran a third experiment using a different set of parafoveal preview conditions.

Experiment 3 included an SL-internal preview condition in which the fifth and sixth letters of a seven-letter word were replaced, as well as a TL-final condition and an SL-final condition. If the pattern of data from Experiment 2 in fact is due to a privileged role that the word-final letter plays in reading, then a preview that disrupts the internal letters in the word but maintains the word-final letter (as in the SL-internal condition) should lead to shorter viewing durations than a preview in which the word-final letter is disrupted (as in both the TL-final and SL-final conditions). In this experiment, the SL-internal condition involved the manipulation of the fifth and sixth letters in order to overcome issues with eccentricity that could not be teased apart from Experiments 1 and 2.

Furthermore, Experiment 3 included the addition of a TL-initial and an SL-initial preview condition. The manipulation of wordinitial letters is yet another way to test the importance of exterior letters in word recognition and the role of eccentricity. Parafoveal word-initial manipulations are close to the fovea and, thus, the extraction of letters from these locations (whether they are TLs or SLs) is highly likely. This hypothesis, based on eccentricity alone, would predict that TL effects should be strong at the word-initial location (in fact, stronger than at a word-internal location as tested in Experiment 2). However, if the word-initial letter plays a special role in word recognition, we may see little or no TL effect at this position. Finally, an identity condition was added as a control baseline. Taken together, these six conditions help give us a more complete picture of letter encoding in the parafovea.

\section{Method}

Participants. Thirty members of the University of Massachusetts at Amherst community participated in the experiment. Just as in the previous two experiments, they all had normal vision or soft contacts, were native speakers of American English, and were naive to the purpose of the experiment. They each received either course credit or monetary compensation $(\$ 5-\$ 8)$ for their time.

Apparatus. The apparatus was the same as that in Experiment 2.

Stimuli. Target stimuli included 102 seven-letter words embedded into single-line sentences containing no more than 77 letters. Target words never occupied the sentence-initial or sentence-final word position. Francis and Kučera (1982) frequencies of target words ranged from 1 per million to 222 per million $(M=35)$ and again represented a variety of word classes. Six parafoveal preview conditions were generated for each target word. Previews (a) were identical to the target word (e.g., acrobat as a preview of acrobat; identity), (b) involved a transposition of the first two letters of the word (e.g., carobat; TL initial), (c) involved a substitution of the first two letters of the word (e.g., nerobat; SL initial), (d) involved a substitution of the fifth and sixth letters of the word (e.g., acroult; SL internal), (e) involved a transposition of the last two letters of the word (e.g., acrobta; TL final), or (f) involved a substitution of the last two letters of the word (e.g., acroblo; SL final). ${ }^{6}$ The same boundary paradigm and counterbalancing procedures used in the first two experiments were again used. Each participant read 17 sentences in each of the 6 preview conditions.

Design and procedure. The procedure was the same as that in Experiments 1 and 2. Comprehension questions occurred after $22 \%$ of the trials, and participants' accuracy ranged from $91 \%$ to $100 \%(M=98 \%)$.

Normative data. Experimental sentences for Experiment 3 were normed for predictability and understandability using the same procedures described in Experiment 1. The overall mean predictability score was less than $1 \%$, indicating that the target words were not predictable from the previous context. Furthermore, all of the target words were rated as understandable within the sentence $(M=6.12)$. None of the participants in either norming procedure (10 in each) participated in the eyetracking portion of the experiment. The experimental sentences and preview conditions are in Appendix C.

\section{Results}

As in Experiments 1 and 2, trials in which the display change triggered too early, the eyetracker lost track of the reader, or in which the participant blinked on the pretarget word, target word, or posttarget word were all discarded. Again, short fixations were combined with fixations on an adjacent letter. Extremely short isolated fixations $(<120 \mathrm{~ms})$ and extremely long fixations $(>600$ $\mathrm{ms}$ ) were eliminated from the data prior to analyses. These trimming procedures resulted in the elimination of $18 \%$ of the data. The mean first fixation duration, single fixation duration, and gaze duration for each of the six parafoveal preview conditions can be found in Table 4.

The six parafoveal preview conditions were analyzed by repeated-measures ANOVAs, with error variance calculated over participants and over items. There was a significant main effect of

\footnotetext{
${ }^{6}$ It should be noted that the TL and SL conditions in all three experiments often created orthographically and phonologically illegal letter strings. In addition, parafoveal preview conditions were not directly controlled on their variations in spatial frequency. It may be interesting to determine how much of an effect these have to the current pattern of results with future research.
} 
Table 4

Means as a Function of Type of Manipulation and Manipulation Location for Experiment 3

\begin{tabular}{lccc}
\hline $\begin{array}{c}\text { Parafoveal } \\
\text { preview } \\
\text { condition }\end{array}$ & $\begin{array}{c}\text { First } \\
\text { fixation }\end{array}$ & $\begin{array}{c}\text { Single } \\
\text { fixation }\end{array}$ & $\begin{array}{c}\text { Gaze } \\
\text { duration }\end{array}$ \\
\hline Identity baseline & 286 & 288 & 301 \\
TL, initial & 313 & 322 & 332 \\
SL, initial & 322 & 334 & 352 \\
SL, internal & 296 & 303 & 312 \\
TL, final & 323 & 327 & 339 \\
SL, final & 314 & 320 & 323 \\
\hline
\end{tabular}

Note. All durations are in milliseconds. $\mathrm{TL}=$ transposed letter; $\mathrm{SL}=$ substituted letter.

preview condition across all viewing duration measures: For first fixation duration, $F_{1}(5,145)=5.986, p<.001$, and $F_{2}(5,505)=$ $1.892, p=.098$; for single fixation duration, $F_{1}(5,145)=9.495$, $p<.001$, and $F_{2}(5,505)=3.261, p<.01$; for gaze duration, $F_{1}(5$, $145)=9.466, p<.001$, and $F_{2}(5,505)=2.418, p<.05$.

Planned pairwise comparisons revealed that the identity condition led to significantly shorter viewing durations than the TLinitial condition, the SL-initial condition, the TL-final condition, and the SL-final condition. These differences were significant across all three viewing duration measures both by participants (all $p$ s $<.01$ ) and by items (all $p$ s $<.05$ ). The difference between the identity condition and the SL-internal condition was significant by participants in single fixation duration, $t_{1}(29)=2.269, p<.05$, and marginally significant by participants in first fixation duration, $t_{1}(29)=1.348, p=.095$, but not significant across any other measures (all $p \mathrm{~s}>.113$ ).

One purpose of Experiment 3 was to extend the examination of TL effects to that at word-initial letter locations. In first fixation duration, although there was a trend for the TL-initial preview condition to lead to shorter fixation durations than the SL-initial preview condition, the 9-ms effect was not significant by participants $(p>.165)$ and only marginally significant by items, $t_{2}(101)=1.412, p=.081$. The 12 -ms effect in single fixation duration showed the same pattern of significance, $t_{1}(29)=1.262$, $p=.109$, and $t_{2}(101)=1.642, p=.053$. The 20 -ms effect in gaze duration was significant by participants, $t_{1}(29)=2.562, p<.01$, but not by items $(p>.245)$. Just as in Experiment 2, there was no TL effect at the word-final letter position. In fact, the pattern of means was in the opposite direction from the facilitatory pattern typically found with TL previews and primes.

Finally, another crucial comparison was the difference between the SL-internal condition and the two final manipulation conditions. The SL-internal condition led to significantly shorter viewing durations than the TL-final condition across all viewing duration measures. This effect was $27 \mathrm{~ms}$ for first fixation duration, $t_{1}(29)=3.732, p<.001$, and $t_{2}(101)=3.145, p<.01,24 \mathrm{~ms}$ for single fixation duration, $t_{1}(29)=2.896, p<.01$, and $t_{2}(101)=$ $3.264, p<.01$, and $27 \mathrm{~ms}$ for gaze duration, $t_{1}(29)=3.274, p<$ .01 , and $t_{2}(101)=3.112, p<.01$. Similarly, the SL-internal condition led to significantly shorter viewing durations than the SL-final condition. This effect was $18 \mathrm{~ms}$ for first fixation duration, $t_{1}(29)=2.597, p<.01$, and $t_{2}(101)=2.467, p<.01,17 \mathrm{~ms}$ for single fixation duration, $t_{1}(29)=2.373, p<.05$, and $t_{2}(101)=$ $3.16, p<.001$, and $11 \mathrm{~ms}$ for gaze duration, $t_{1}(29)=1.507, p=$ .072 , and $t_{2}(101)=2.182, p<.05$.

\section{Discussion}

Across all dependent measures, the SL-internal condition, which preserved the word-final letter, led to shorter viewing times than both the TL-final condition and the SL-final condition. In these two latter conditions, letter identity and letter position information was left intact for the first five letters but not for the sixth or (crucially) the seventh. This finding provides further evidence that the word-final letter is important for word recognition during reading. The fact that the SL-internal condition led to shorter viewing times than even the TL-final condition (which contained all of the correct letter identity information) indicates that the extraction of letter identity information from the word-final letter position is dependent on absolute letter position.

Although the pattern of means suggests that the TL-initial condition was a better preview than the SL-initial condition, the statistical analyses indicate that this difference is not strong. It should be noted that the TL effect at the initial position is not as strong as that found at internal letter locations (see Experiment 2, Conditions 2 and 3). Although the TL effects were 9, 12, and 20 $\mathrm{ms}$ for the three viewing duration measures (first fixation duration, single fixation duration, and gaze duration, respectively) at the initial letter position, the TL effects were 19, 20, and $28 \mathrm{~ms}$ at the internal letter positions. So, although word-initial letters located in the parafovea are closest to the fovea and therefore most likely to be acquired on the fixation prior to fixating the word, the TL effect at this position was not as strong as the effect further into the word. This finding suggests that readers have difficulty parafoveally extracting letter information outside of absolute letter position at the word-initial letter position. Thus, it is likely that identification of the word-initial letter, just as that of the word-final letter, is dependent on absolute letter position and plays a special role in word recognition.

Finally, just as in Experiments 1 and 2, the identity condition provided the best preview. The identity preview led to significantly shorter viewing durations than the TL-initial, SL-initial, TL-final, and SL-final conditions and occasionally led to shorter viewing durations than the SL-internal condition. Again, this finding indicates that correct letter position does play a significant role in reading, especially when the word-initial and the word-final letters are involved.

\section{General Discussion}

Three experiments were conducted to examine the role of letter identity and letter position within the context of silent reading. Before fixating on a given target word, readers were provided with a parafoveal preview that differed in the amount of useful letter identity and letter position information it provided. In Experiments 1 and 2, previews were either (a) identical to the target word, (b) a transposition of two internal and adjacent letters, (c) a substitution of two internal and adjacent letters, (d) a transposition of the two final letters, or (e) a substitution of the two final letters. In Experiment 3, a further set of preview conditions was used to explore the importance of word-initial and word-final letters. Pre- 
views were either (a) identical to the target word, (b) a transposition of the first two letters, (c) a substitution of the first two letters, (d) a substitution of two internal and adjacent letters, (e) a transposition of the two final letters, or (f) a substitution of the two final letters.

In Experiment 1, when five-letter words were used as targets, the identity condition led to shorter viewing durations than the other conditions. The TL preview conditions provided greater preview benefit than the SL preview control conditions at both letter manipulation positions. In Experiment 2, when seven-letter words were used as targets, the identity condition again led to shorter viewing durations than the two final manipulation conditions but did not differ from the TL-internal condition. Also, although the TL effect was significant at the internal letter position location, the TL effect was not present at the final letter position location. Experiment 3 also confirmed the lack of a TL effect at the word-final letter location for longer words and showed only a trend in the data to support a TL effect at the word-initial position. The findings extend previous work done with response time tasks to show that TL effects exist in the context of normal silent reading at the parafoveal level. These experiments also indicate that although letter identity information can be extracted from the parafovea outside of absolute letter position from the first five letters of the word to the right of fixation, correct letter position facilitates word recognition. Furthermore, both the word-initial and the wordfinal letter positions play an important role in the parafoveal processing of words.

In the current experiments, TL nonwords led to significantly shorter viewing durations (in first fixation duration, single fixation duration, and gaze duration) than SL nonword controls, indicating that TL nonwords are more similar to their base words than controls that involve a substitution of two letters. The presence of a TL nonword (even in the parafovea) activates the lexical representation of its base word, leading to faster response times in response time tasks and shorter viewing durations in silent reading. These findings support the TL effects previously documented in the literature (Andrews, 1996; Chambers, 1979; Christianson et al., 2005; Forster et al., 1987; Holmes \& Ng, 1993; O'Connor \& Forster, 1981; Perea \& Lupker, 2003a, 2003b, 2004a; Taft \& van Graan, 1998) and extend them to normal silent reading and parafoveal processing.

In Experiment 1, the same 120 target words (and prime conditions) used by Perea and Lupker (2003b) were embedded into sentences to examine TL effects in the context of silent reading. Perea and Lupker (2003b) found that response times (in milliseconds) for targets in the identity, TL-internal, SL-internal, TL-final, and SL-final conditions were 523, 556, 586, 554, and 567, respectively, in the masked priming lexical decision task. Identity previews yielded the fastest response times followed by the two TL prime conditions. The two SL conditions led to the longest reaction times. The data from Experiment 1 yielded a similar pattern of data; single fixation durations for each of the five conditions were (in milliseconds) 270, 276, 292, 282, and 292. In Perea and Lupker's (2003b) study, the 30-ms TL effect for the internal manipulations was significant $(p<.001)$, whereas the TL effect for the final manipulations was only marginally significant ( $p=$ .07). In contrast, in Experiment 1, both TL-internal and TL-final manipulations led to significantly shorter viewing durations than their SL preview control conditions. The interaction between letter manipulation type and letter position was not significant ( $p=$ .371 ), although this interaction is not reported by Perea and Lupker (2003b). Of note, Perea and Lupker (2003b) reported as a footnote that when they collapsed the data from their first two experiments, the TL effect at the final manipulation position became significant $(p<.02)$. Therefore, it is reasonable to assume that-to some degree-similar processes are at work in both masked form priming and parafoveal preview during silent reading. Any slight differences can be attributed to the fact that all stimuli in Perea and Lupker's (2003b) experiment were presented at the fovea, whereas the previews in the current experiments were all parafoveal.

\section{Letter Identity and Letter Position}

One of the primary goals of the current experiments was to examine the importance of letter identity and letter position in word recognition during reading. In Experiments 1 and 2, there was a significant main effect of letter manipulation type across all three viewing duration measures. In all cases, the TL conditions led to significantly shorter durations than the SL conditions. This finding indicates that readers are able to extract useful letter identity information from the parafovea outside of absolute letter position. Had this process of extracting letter identity information been dependent on absolute letter position, there would not have been any difference among these preview types, because in each case, the reader is presented with a nonword preview in which three correct letters are located in their correct letter position. In the internal manipulations from Experiment 1, for example, both the TL preview condition (celrk as the preview for clerk) and the SL preview condition (cohrk as the preview for clerk) provide the correct letter identity and letter position information at Letter Positions 1, 4, and 5. The fact that readers were able to extract letter identity information from the $e$ and $l$ in the nonword celrk even though they were not in their correct letter position indicates that letters are not processed (at least at the parafoveal level) solely through a specific letter string channel, but rather are coded by their approximate letter position (for a similar argument, see Andrews, 1996; Peressotti \& Grainger, 1999; Ratcliff, 1981; Rumelhart \& McClelland, 1982). Given that letter identities can be processed outside of absolute letter position, perhaps letter positions (especially internal letter positions) are not encoded well or take longer to encode than letter identities (Adams, 1979). That is, when a TL nonword like jugde occurs as a prime or a parafoveal preview, the letters $j, u, g, d$, and $e$ are identified and begin to activate the lexical representation of the word judge before the system realizes that the $g$ and $d$ are in the wrong letter position. ${ }^{7}$

It is interesting to ask what the time course is in letter identification and letter position encoding. Although the answer to this question is not directly addressed by the present experiments, analyses of two other dependent measures help shed some light on the subject. Specifically, if the robust TL effects found in these experiments are localized to a very early point in parafoveal processing, we may see differences in the eye movement record

\footnotetext{
${ }^{7}$ Throughout this article, we have taken a highly letter-dominated view of word recognition. However, we acknowledge that there are likely several other levels of processing involved in lexical access including lower, perceptual levels (e.g., course visual cues, letter features) as well as higher, multiletter levels (e.g., bigrams, trigrams).
} 
before participants fixate on the target word. The skipping rate of the target word and the first pass fixation time on the pretarget word would then be greater for TL nonwords than for SL nonwords (Pollatsek, Rayner, \& Balota, 1986; Reichle, Pollatsek, Fisher, \& Rayner, 1998). However, the main effect of type of manipulation was not significant by participants or by items in either of these two analyses in any of the three current experiments (all $p s>.10){ }^{8}$

It should be noted, though, that the extent to which readers are able to extract letter identity information outside of absolute letter position is not fully addressed by these experiments. In all three experiments, only adjacent letter manipulations were used to explore the role of letter identity and letter position. Whether these parafoveal priming effects would exist (and how strong they would be) if nonadjacent manipulations (e.g., acborat for acrobat) or multiple manipulations (e.g., arcobta for acrobat) were used as parafoveal previews is unknown from the current studies. (However, more recently, Johnson, in press, found that parafoveal TL effects exist even when nonadjacent letters are manipulated.) Finally, although Experiment 3 does go beyond the first two experiments in addressing the nature of TL effects at word-initial letter locations, there are still a number of other manipulations that are absent from these three experiments that would provide further information about how letters are encoded in visual word recognition.

Although letter identity can be extracted from the fovea and parafovea outside of absolute letter position, letter position is still important in word recognition in reading. If letter identities were extracted and processed completely independent of some sort of absolute or relative letter position, readers would be unable to successfully decode anagrams. The words spot, tops, opts, post, pots, and stop would all activate the same letter identities and, in the absence of any position information, would all be perceived similarly. A comparable point can be made with nonword scrambles in which the letters of a nonword can be rearranged to correctly form a word. The letters in the nonwords rtuercisp, cehpys, osanta, and sabbor, for example, can be rearranged in only one way to form English words. Yet, although readers can process each of these letters independent of their letter position, they are often unsuccessful at activating their appropriate base word. ${ }^{9}$ Thus, although letter identities can be extracted outside of absolute letter position, correct letter position plays an important role in this extraction process.

The fact that letter identity is important in word recognition is also supported by the experiments reported here. First of all, the results from Experiments 2 and 3 indicate that the identification of word-initial and word-final letters is dependent on letter position. For these longer words, TL effects were weak (as in the wordinitial location) or nonexistent (as in the word-final location) at these exterior letter positions. These findings support the notion that both word-initial and word-final letters play a crucial role in visual word recognition, even during parafoveal processing.

The second piece of evidence comes from an exploration of the identity condition in relation to the other conditions in these three experiments. The identity condition, which provided correct letter identity and letter position information, often led to significantly shorter viewing durations than the other conditions. Some notable exceptions are in the TL-internal condition from Experiment 2 and the SL-internal condition from Experiment 3. In these cases, the parafoveal previews provided a sufficient amount of correct information so that viewing durations closely mimicked that of the identity condition. For example, the TL-internal preview condition from Experiment 2 provided the reader with correct letter identity information, correct letter position information at five of seven letter positions $(1,2,3,6$, and 7), and correct word-final letter information.

These findings are consistent with those previously reported (Christianson et al., 2005; Forster et al., 1987; Humphreys et al., 1990; O’Connor \& Forster, 1981; Perea \& Lupker, 2003a, 2003b). Although some of the studies report no significant differences between an identity condition and a TL-condition (often a TLinternal manipulation; e.g., Christianson et al., 2005; Forster et al., 1987), the pattern of means in these studies indicates that the identity condition is always the most facilitative prime condition. In a prime-target task in which participants were asked to identify briefly presented letters within a random letter string, Humphreys et al. (1990) found that letter identification performance increased as the prime shared more letters (in their correct letter position) with the target. Of note, as the number of letters in common between the primes and targets increased, the participants' performance did so nonlinearly, so that a prime with three letters in common with the target yielded more facilitation than the sum of the priming effects from one and two letter primes. Thus, not only is correct letter position important, but the benefits of correct letter position increase nonlinearly.

\section{Letter Identity in the Parafovea}

As mentioned earlier, Rayner et al. (1982) concluded that readers do not use letter information from more than the first three letter positions of the word to the right of fixation. If, however, readers were only able to extract letter identity information from the first three letters of the word to the right of fixation in the experiments reported here, we would have expected to see no significant differences between the identity condition and either of the two final manipulation conditions (TL-final and SL-final conditions). In Experiment 1, for example, five-letter words were used as target stimuli. In these three parafoveal preview conditions, the first three letters of the word to the right of fixation were available

\footnotetext{
${ }^{8}$ Another factor that is known to affect parafoveal preview benefit is the launch site of the saccade entering the target word. When launch site was examined, in Experiment 1 there was a marginal interaction ( $p=.054$ for participants and $p=.13$ for items) between type of manipulation and launch site, with the data for the latter variable divided into near (four letters or less from the beginning of the target word) and far (more than four letters). The nature of the interaction was that for near launch sites, the TL effect was greater than for far launch sites. Likewise, in Experiment 2, there was a marginal interaction that was significant by items $(p<.05)$ but not significant by participants. Again, this interaction was characterized by a greater TL effect for near versus far launch sites. Although in the current article we specify that the results indicate that letters can be extracted from the parafovea outside of absolute letter position from the first five letters of the word to the right of fixation, we acknowledge that this distance is only an average. The true boundary is likely to differ from word to word as a function of launch site and perhaps even as a function of lexical factors as well.

9 The answers to these nonword jumbles are rtuercisp-scripture, cehpys-psyche, osanta-sonata, and sabbor-absorb.
} 
to the reader and in their correct letter position. It was in the letters beyond this third letter position that these three conditions began to differ. Therefore, the fact that significant differences were found in comparing fixation times from the identity condition with those from these final manipulation conditions indicates that readers are able to extract letter identity information from further than just the first three letters of the word to the right of fixation.

Further support comes from Experiment 2. Across all viewing duration measures, the TL-internal condition led to shorter viewing durations than the SL-internal condition. In all of these seven-letter previews, these two conditions were equivalent at Letter Positions $1,2,3,6$, and 7 . The only difference between these two conditions was in the letter identity information that they provided at Letter Positions 4 and 5. The fact that the TL preview condition led to shorter viewing durations than the SL preview condition indicates that readers were able to extract letter identity information from these letter positions and use it on fixating the target word to facilitate word recognition. Because the SL preview conditions were visually similar to that of their respective TL preview conditions, these effects cannot be attributed to the extraction of word shape information (see also Table 2). Rather, readers were extracting useful letter identity information from the first five letters of the word to the right of fixation. ${ }^{10}$

Also in Experiment 2, differences between the identity condition and the two final manipulation conditions were significant across all viewing duration measures. However, unlike the internal manipulations, the TL-final condition did not provide a significantly greater preview benefit than the SL-final condition. Therefore, we cannot conclude that the differences between the identity condition and the final manipulation conditions are a result of the extraction of letter identity information from further than the first five letters of the word to the right of fixation. Rather, we propose that readers were gaining useful letter identity information from the first five letters of the word to the right of fixation as well as gaining information about the word-final letter(s) of the word to the right. This information, which is present in the identity condition but not in either of the two final manipulation conditions (in which the final letters are denied), is combined with information presented on fixation, thereby facilitating word recognition. The results from Experiment 3 also support the privileged role of the word-final letter in word recognition. The SL-internal condition, which preserved the word-final letter, led to shorter viewing durations than both the TL-final condition and the SL-condition, both of which disrupted the word-final letter.

Giving special importance to the word-final letter in a letter string also helps explain why in Experiment 2, the identity condition did not differ significantly in the amount of parafoveal benefit it provided when compared with the TL-internal condition, but it did lead to significantly shorter viewing durations when compared with the TL-final condition. In each of these two TL conditions, five out of the seven letters within the letter string were correct and in their correct letter position. The difference between these two TL conditions, however, is that, in the TL-internal condition, the reader has correct letter identity and letter position information at Letter Positions 1, 2, 3, 6, and 7 within the letter string (preserving the word-final letter), whereas in the TL-final condition, the reader has access to this information at Letter Positions 1, 2, 3, 4, and 5 (disrupting the word-final letter).
Yet in Experiment 1, the TL effect was significant for both internal and final manipulations. That is, even when the word-final letter was disrupted, fixation durations were shorter following TL-final previews than SL-final previews. In reconciling these apparent differences, we should note that the target words in Experiment 1 were considerably shorter than those in Experiments 2 and 3. In Experiment 1, the word-final letter was only five characters into the word to the right of fixation, a distance that we have argued that letters can be extracted outside of absolute letter position. For Experiments 2 and 3, in contrast, the word-final letter was seven characters into the word to the right of fixation. At this distance, letters cannot be extracted outside of their absolute letter position; the word-final letter is able to be extracted but only within its letter position. Furthermore, in Experiment 1, both the TL-final and SL-final conditions led to significantly longer fixation durations than the identity condition in which the word-final letter was preserved. Thus, even the results from Experiment 1 suggest that the word-final letter is important in visual word recognition.

Finally, a cross-experiment analysis comparing the difference in preview benefit from the identity condition with the SL-internal conditions from Experiments 2 and 3 also indicates that readers are able to extract more than three letters from the word to the right of fixation. Although in Experiment 2, the SL-internal condition involved the manipulation of the fourth and fifth letters in the word (e.g., acrdeat), in Experiment 3, the SL-internal condition involved the manipulation of the fifth and sixth letters in the word (e.g., acroult). A contrast comparing the difference between the SLinternal condition with the identity condition across these two experiments indicated that SL-internal previews are closer to the identity condition in Experiment 3 than in Experiment 2. That is, previews in which the correct letters were presented in Letter Positions 1, 2, 3, 4, and 7 were better previews than those in which correct letters were presented in Letter Positions 1, 2, 3, 6, and 7. In Experiment 2, the differences between the SL-internal condition and the identity condition were 25,28 , and $37 \mathrm{~ms}$ for first fixation duration, single fixation duration, and gaze duration, respectively, whereas for Experiment 3, these differences were much smaller (10, 15, and $11 \mathrm{~ms}$, respectively). This contrast was significant for first fixation duration, $t_{1}(62)=1.77, p<.05$, and $t_{2}(131)=1.75$, $p<.05$, single fixation duration, $t_{1}(62)=1.53, p=.065$, and $t_{2}(127)=2.07, p<.05$, and gaze duration, $t_{1}(62)=2.59, p<.01$,

\footnotetext{
${ }^{10}$ Looking back to Rayner et al.'s (1982) study, some key points should be made. First, the conclusion made by Rayner et al. (1982) was based on a comparison made between a whole word preview and a nontruncated three-letter preview in which the first three letters of all words were presented, irrespective of word length. Thus, for words shorter than four letters in length, these two previews were identical. Because the stimuli used by Rayner et al. (1982) contained a number of short words, their critical comparison is prone to be a very small effect (Inhoff, 1990). Second, although the differences were not significant, the pattern of data that emerged from the Rayner et al. (1982) study suggests a trend (in both overall reading rate and in forward fixation duration) indicating that letter identity processing does extend beyond the first three letters of the word to the right of fixation. Other studies have also found evidence suggesting that letter identity information is likely to be extracted from further than three-letter positions of the word to the right of fixation (Briihl \& Inhoff, 1995; Inhoff, 1989a, 1989b; Inhoff, 1990).
} 
and $t_{2}(130)=2.26, p<.05$. This analysis supports those previously discussed to show that readers are able to extract information from the first five letters of the word to the right of fixation plus the word-final letter and use it in reading.

The differences here are quite large and suggest that the extraction of useful letter identity information from the parafovea leads to nonlinear differences in performance. Although a complete analysis of this patterning cannot be conducted because of the absence of an SL condition in which the second and third letters were substituted and an SL condition in which the third and fourth letters were substituted, these apparent nonlinearities are in accord with the findings from Humphreys et al. (1990). As reported earlier, Humphreys et al. found that participants' performance increased nonlinearly as the number of letters shared between primes and targets increased. A similar effect is likely occurring in the present experiments; having four adjacent correct letters in the parafovea (Experiment 3 ) is vastly more beneficial than having only three adjacent correct letters (Experiment 2).

\section{Models of Visual Word Recognition}

The fact that TL effects exist in response time tasks (and, as shown in the current experiments, in silent reading) causes problems for models of word recognition that assume a channelspecific coding scheme for letter identities and letter positions. These include the multiple read-out model (Grainger \& Jacobs, 1996), the dual-route cascaded model (Coltheart et al., 2001), the interactive activation model (McClelland \& Rumelhart, 1981), and the activation-verification model (Paap et al., 1982). Contextsensitive encoding, such as with the "wickelfeature" scheme of the connectionist model of Seidenberg and McClelland (1989), cannot account for TL effects either. There are, however, some current models that can account for TL effects using other coding schemes. These are the SERIOL model (Whitney, 2001), the open-bigram model (Grainger \& van Heuven, 2003; Grainger, Granier, Farioli, Van Assche, \& van Heuven, 2006), the SOLAR model (Davis, 1999), and the overlap model (Gómez, Perea, \& Ratcliff, 2003). These models correctly predict that TL nonwords are more similar to their base words than SL nonwords, the identity condition provides the greatest activation, and the similarity between a TL nonword and its base word is greater for longer words than for shorter words. Although all of these predictions were confirmed in the results of the present study, each of these models is only designed to make predictions in the context of reading a single word presented at the foveal level. Further modeling attempts should incorporate the results from the current experiments, extending the flexibility of letter coding to parafoveal processing and sentence reading. For example, none of these models are currently able to account for the differential TL effects in short versus long words; that is, although parafoveal TL effects are equally strong at internal versus final letter positions in short words, parafoveal TL effects are absent from the word-final position in longer words. This is likely directly related to the nature of acuity limitations in the context of parafoveal processing of letters during normal silent reading.

In summary, TL effects, which previously had been found in response time tasks, also exist in normal silent reading at the parafoveal level (see Rayner, White, Johnson, \& Liversedge, 2006, for a recent demonstration of foveal TL effects within the context of text reading). Readers are able to successfully extract letter identity information from the parafovea outside of absolute letter position and use it to facilitate word recognition. However, correct letter identity when combined with correct letter position facilitates this process to an even greater degree. Furthermore, these effects differ as a function of word length and as a function of the letter position, informing current models of word recognition and providing evidence for the differential importance of varying letter positions within a word.

\section{References}

Adams, M. J. (1979). Models of word recognition. Cognitive Psychology, $11,133-176$.

Andrews, S. (1996). Lexical retrieval and selection processes: Effects of transposed-letter confusability. Journal of Memory and Language, 35, 775-800.

Briihl, D., \& Inhoff, A. W. (1995). Integrating information across fixations during reading: The use of orthographic bodies and of exterior letters. Journal of Experimental Psychology: Learning, Memory, and Cognition, 21, 55-67.

Bruner, J. S., \& O'Dowd, D. (1958). A note on the informativeness of parts of words. Language and Speech, 1, 98-101.

Chambers, S. M. (1979). Letter and order information in lexical access. Journal of Verbal Learning and Verbal Behavior, 18, 225-241.

Christianson, K., Johnson, R. L., \& Rayner, K. (2005). Letter transpositions within and across morphemes. Journal of Experimental Psychology: Learning, Memory, and Cognition, 31, 1327-1339.

Coltheart, M., Rastle, K., Perry, C., Ziegler, J., \& Langdon, R. (2001). DRC: A dual route cascaded model of visual word recognition and reading aloud. Psychological Review, 108, 204-256.

Davis, C. J. (1999). The self-organising lexical acquisition and recognition (SOLAR) model of visual word recognition. Unpublished doctoral dissertation, University of New South Wales, Sydney, New South Wales, Australia.

Davis, C. J., \& Andrews, S. (2001, April). Inhibitory effects of transposedletter similarity for words and non-words of different lengths. Paper presented at the 35th Australian Experimental Psychology Conference, Melbourne, Victoria, Australia.

De Moor, W., \& Brysbaert, M. (2000). Neighborhood-frequency effects when primes and targets are of different lengths. Psychological Research, 63, 159-162.

Forster, K. I., Davis, C., Schoknecht, C., \& Carter, R. (1987). Masked priming with graphemically related forms: Repetition or partial activation? Quarterly Journal of Experimental Psychology: Human Experimental Psychology, 39(A), 211-251.

Francis, W., \& Kučera, H. (1982). Frequency analysis of English usage: Lexicon and grammar. Boston: Houghton Mifflin.

Friedmann, N., \& Gvion, A. (2001). Letter position dyslexia. Cognitive Neuropsychology, 18, 673-696.

Gómez, P., Perea, M., \& Ratcliff, R. (2003). A model of the coding of letter positions: The overlap model. Poster presented at the 45th Annual Meeting of the Psychonomic Society, Vancouver, British Columbia, Canada.

Grainger, J., Granier, J. P., Farioli, F., Van Assche, E., \& van Heuven, W. (2006). Letter position information and printed word perception: The relative-position priming constraint. Journal of Experimental Psychology: Human Perception and Performance, 32, 865-884.

Grainger, J., \& Jacobs, A. M. (1996). Orthographic processing in visual word recognition: A multiple read-out model. Psychological Review, $103,518-565$.

Grainger, J., \& van Heuven, W. (2003). Modeling letter position coding in printed word perception. In P. Bonin (Ed.), The mental lexicon (pp. 1-24). New York: Nova Science. 
Holmes, V. M., \& Ng, E. (1993). Word-specific knowledge, wordrecognition strategies, and spelling ability. Journal of Memory and Language, 32, 230-257.

Humphreys, G. W., Evett, L. J., \& Quinlan, P. T. (1990). Orthographic processing in visual word recognition. Cognitive Psychology, 22, 517560

Inhoff, A. W. (1989a). Lexical access during eye fixations in reading: Are word access codes used to integrate lexical information across interword fixations? Journal of Memory and Language, 28, 444-461.

Inhoff, A. W. (1989b). Parafoveal processing of words and saccade computation during eye fixations in reading. Journal of Experimental Psychology: Human Perception and Performance, 15, 544-555.

Inhoff, A. W. (1990). Integrating information across eye fixations in reading: The role of letter and word units. Acta Psychologica, 73, 281-297.

Jacobs, A. M., Rey, A., Ziegler, J. C., \& Grainger, J. (1998). MROM-p: An interactive activation, multiple readout model of orthographic and phonological processes in visual word recognition. In J. Grainger \& A. M. Jacobs (Eds.), Localist connectionist approaches to human cognition (pp. 147-188). Mahwah, NJ: Erlbaum.

Johnson, R. L. (in press). The flexibility of letter coding: Nonadjacent letter transposition effects in the parafovea. In R. Van Gompel, M. Fisher, W. Murray, \& R. L. Hill (Eds.), Eye movements: A window on mind and brain. Oxford, England: Elsevier.

Jordan, T. R. (1990). Presenting words without interior letters: Superiority over single letters and influence of postmask boundaries. Journal of Experimental Psychology: Human Perception and Performance, 16, 893-909.

Jordan, T. R., Thomas, S. M., Patching, G. R., \& Scott-Brown, K. C. (2003). Assessing the importance of letter pairs in initial, exterior, and interior positions in reading. Journal of Experimental Psychology: Learning, Memory, and Cognition, 29, 883-893.

Legge, G. E., Mansfield, J. S., \& Chung, S. T. L. (2001). Psychophysics of reading XX. Linking letter recognition to reading speed in central and peripheral vision. Vision Research, 41, 725-743.

McClelland, J. L., \& Rumelhart, D. E. (1981). An interactive activation model of context effects in letter perception: Part I. An account of basic findings. Psychological Review, 88, 375-407.

McConkie, G. W., \& Rayner, K. (1975). The span of the effective stimulus during a fixation in reading. Perception \& Psychophysics, 17, 578-586.

McConkie, G. W., \& Zola, D. (1979). Is visual information integrated across successive fixations in reading? Perception \& Psychophysics, 25, 221-224.

McCusker, L. X., Gough, P. B., \& Bias, R. G. (1981). Word recognition inside out and outside in. Journal of Experimental Psychology: Human Perception and Performance, 7, 538-551.

O'Connor, R. E., \& Forster, K. I. (1981). Criterion bias and search sequence bias in word recognition. Memory \& Cognition, 9, 78-92.

Paap, K. R., Newsome, S. L., McDonald, J. E., \& Schvaneveldt, R. W. (1982). An activation-verification model for letter and word recognition: The word superiority effect. Psychological Review, 89, 573-594.

Perea, M. (1998). Orthographic neighbours are not all equal: Evidence using an identification technique. Language and Cognitive Processes, 13, 77-90.

Perea, M., \& Carreiras, M. (1998). Effects of syllable frequency and syllable neighborhood frequency in visual word recognition. Journal of Experimental Psychology: Human Perception and Performance, 24, $134-144$.

Perea, M., \& Fraga, I. (2006). Transposed-letter and laterality effects in lexical decision. Brain and Language, 97, 102-109.

Perea, M., \& Lupker, S. J. (2003a). Does jugde activate COURT?
Transposed-letter similarity effects in masked associative priming. Memory \& Cognition, 31, 829-841.

Perea, M., \& Lupker, S. J. (2003b). Transposed-letter confusability effects in masked form priming. In S. Kinoshita \& S. J. Lupker (Eds.), Masked priming: The state of the art (pp. 97-120). New York: Psychology Press.

Perea, M., \& Lupker, S. J. (2004a). Can CANISO activate CASINO? Transposed-letter similarity effects with nonadjacent letter positions. Journal of Memory and Language, 51, 231-246.

Perea, M., \& Lupker, S. J. (2004b, November). The effect of transposed letter stimuli in visual word recognition. Paper presented at the 45th Annual Meeting of the Psychonomic Society, Minneapolis, MN.

Perea, M., \& Rosa, E. (2002). Does "whole word shape" play a role in visual word recognition? Perception \& Psychophysics, 64, 785-794.

Perea, M., Rosa, E., \& Gómez, C. (2005). The frequency effect for pseudowords in the lexical decision task. Perception \& Psychophysics, 67, 301-314.

Peressotti, F., \& Grainger, J. (1999). The role of letter identity and letter position in orthographic priming. Perception \& Psychophysics, 61, 691706.

Pollatsek, A., Lesch, M., Morris, R. K., \& Rayner, K. (1992). Phonological codes are used in integrating information across saccades in word identification and reading. Journal of Experimental Psychology: Human Perception and Performance, 18, 148-162.

Pollatsek, A., Rayner, K., \& Balota, D. A. (1986). Inferences about eye movement control from the perceptual span in reading. Perception \& Psychophysics, 40, 123-130.

Ratcliff, R. (1981). A theory of order relations in perceptual matching. Psychological Review, 88, 552-572.

Rayner, K. (1975). The perceptual span and peripheral cues in reading. Cognitive Psychology, 7, 65-81.

Rayner, K. (1998). Eye movements in reading and information processing: 20 years of research. Psychological Bulletin, 124, 372-422.

Rayner, K., McConkie, G. W., \& Zola, D. (1980). Integrating information across eye movements. Cognitive Psychology, 12, 206-226.

Rayner, K., \& Pollatsek, A. (1989). The psychology of reading. Englewood Cliffs, NJ: Prentice Hall.

Rayner, K., Well, A. D., Pollatsek, A., \& Bertera, J. H. (1982). The availability of useful information to the right of fixation in reading. Perception \& Psychophysics, 31, 537-550.

Rayner, K., White, S., Johnson, R. L., \& Liversedge, S. (2006). Raeding wrods with jubmled lettres: There's a cost. Psychological Science, 17, 192-193.

Reichle, E. D., Pollatsek, A., Fisher, D. L., \& Rayner, K. (1998). Toward a model of eye movement control in reading. Psychological Review, 105, $125-157$.

Rumelhart, D. E., \& McClelland, J. L. (1982). An interactive activation model of context effects in letter perception: Part 2. The contextual enhancement effect and some tests and extensions of the model. Psychological Review, 89, 60-94.

Schoonbaert, S., \& Grainger, J. (2004). Letter position coding in printed word perception: Effects of repeated and transposed letters. Language and Cognitive Processes, 19, 333-367.

Seidenberg, M. S., \& McClelland, J. L. (1989). A distributed, developmental model of word recognition and naming. Psychological Review, $96,523-568$.

Taft, M., \& van Graan, F. (1998). Lack of phonological mediation in a semantic categorization task. Journal of Memory and Language, 38, 203-224.

Whitney, C. (2001). How the brain encodes the order of letters in a printed word: The SERIOL model and selective literature review. Psychonomic Bulletin \& Review, 8, 221-243. 


\section{Appendix A}

\section{Experimental Sentences and Preview Conditions in Experiment 1}

The voters argued that they deserve (lower, loewr, loanr, lowre, lowno) lower taxes and better schools.

Aunt Sue wore a thick (glove, golve, gatve, gloev, gloac) glove on each hand to protect her while gardening.

Did the old farmer (spray, spary, sposy, sprya, sprge) spray insecticide over his corn crops this year?

Matt found out that his little sister (tells, tlels, tfols, telsl, telnf) tells secrets behind his back.

Even a fairly minor (sleet, selet, satet, slete, slefo) sleet storm can cause thousands of dollars in damage.

The busy grocery store (clerk, celrk, cohrk, clekr, clefn) clerk accidentally gave me back the wrong change.

In just one year, the average (miner, mienr, miosr, minre, minvo) miner extracts 8,000 tons of coal.

Megan took the gray (scarf, scraf, scnef, scafr, scatn) scarf out of the washer and put it in the dryer.

The harsh winters freeze (lakes, laeks, laots, lakse, lakna) lakes across the entire state of Minnesota.

The kids were thankful that the huge (couch, cuoch, caech, couhc, couln) couch covered the hole in the wall.

I have found that the longer (river, rievr, rianr, rivre, rivso) river trips have better scenery and rapids.

The fans saw the tennis player (sneer, sener, sacer, snere, snevo) sneer viciously at his opponent.

I think the wooden (clock, colck, catck, clokc, clols) clock hanging in the dining room stopped working.

To perform his last (magic, maigc, maoyc, magci, magso) magic trick that day, the magician needed a volunteer.

Jupiter's complex (cloud, cluod, clead, clodu, cloto) cloud formations have yet to be fully understood.

On Friday, we saw the expert (train, trian, troen, trani, traso) train inexperienced employees at the garage.

The crime rate within urban (jails, jials, jeols, jaisl, jaink) jails continues to rise each year.

The label said the item contained pure (fruit, friut, freot, fruti, frulo) fruit juice from Florida.

The young girl kept the golden (coins, cions, cuens, coisn, coivc) coins securely in her pocket.

It was fun to blow (round, ruond, reand, roudn, rouks) round bubbles at the bride and groom on Saturday.

Heidi outlined the human (needs, nedes, netas, neesd, neent) needs specific to low income families.

When moving, you should load (heavy, hevay, henoy, heayv, heajn) heavy furniture onto the truck first.

The highly capable (pilot, pliot, pfeot, pilto, pilke) pilot maneuvered the plane out of enemy territory.

The test was hard, but they were surely (given, gievn, giosn, givne, givca) given ample time to study.

Weighing 14 pounds, the largest (pearl, paerl, puorl, pealr, peatn) pearl measures 5.5 inches in diameter.

The black and white photograph of the rural (barns, banrs, bascs, barsn, barcx) barns earned a blue ribbon.

Walk the narrow (board, baord, buerd, boadr, boatn) board carefully to reach the west side of the stream.
Brian and Natalie went to the empty (study, sutdy, sehdy, stuyd, stufg) study to continue their debate.

Jill gasped when she saw her brother David (stick, sitck, sofck, stikc, stifn) stick waffles into the VCR.

The children's lovely (faces, faecs, faons, facse, facno) faces charmed me into buying lemonade from them.

The visitors watched the Yankee (mount, muont, maent, moutn, moulm) mount horses at the battle reenactment.

In Mississippi, the highest (hills, hlils, hfels, hilsl, hilnt) hills rise only 800 feet above sea level.

Jim saw the band (march, macrh, masnh, marhc, martn) march proudly onto the field and into their formation.

The sensitive microphone allowed us to record (faint, fanit, faset, faitn, failc) faint noises easily.

The researcher examined (fatal, faatl, faefl, fatla, fatfe) fatal bacteria under a microscope in her lab.

Sadly, the rapid (creek, cerek, cusek, creke, crela) creek swept the child's toy sailboat away.

The citizens saw the mayor (frown, forwn, fenwn, fronw, frosc) frown following the election results.

The counseling program will enable (angry, anrgy, anspy, angyr, angjn) angry couples to work through issues.

We watched in disbelief as the tall (tower, toewr, tounr, towre, townu) tower collapsed in New York City.

The wildlife you encounter when you climb (above, abvoe, abnue, aboev, abois) above tree line is distinctive.

Inside the building, silent (monks, mokns, motcs, monsk, monvt) monks meditated prayerfully on Scripture.

I had a pretty (rough, ruogh, reagh, rouhg, routp) rough semester last year but managed to pass every class.

Betsy had to fully (bathe, bahte, bakfe, bateh, batok) bathe herself after mud wrestling with her friends.

Dr. McKenzie made a useful (point, piont, peant, poitn, poifs) point regarding graduate school admissions.

A musical prodigy, Mozart could compose (whole, whloe, whtae, whoel, whoak) whole symphonies by age nine.

The tired slave (lifts, litfs, likls, lifst, lifvl) lifts large bales of hay in the heat of the afternoon.

It was when the proud (thief, tihef, tefef, thife, thita) thief boasted about his acts that he got caught.

Upon entering tenth grade, the size twelve (shoes, sheos, shuas, shose, shovo) shoes didn't fit him anymore.

After he bought the bike, John had to adjust (bolts, botls, bokfs, bolst, bolnf) bolts found under the seat.

Tammy had to count (heads, haeds, houds, heasd, heavf) heads quickly to ensure that all children were there.

You should wear the yellow (skirt, skrit, sknot, skitr, skifs) skirt tonight when you go to the movies.

Unlike my twin sister Donna, I prefer (curly, culry, cufny, curyl, curgt) curly haired men with brown eyes.

Michael tried to identify the unusual (plant, palnt, pofnt, platn, plafs) plant using his nature guide.

Although I was mostly (awake, awkae, awfoe, awaek, awaot) awake during the exam, I fell asleep afterward. 
After Tyler finished his daily (Bible, Bilbe, Bitde, Bibel, Bibot) Bible reading, he said his prayers.

The child watched the adult (shave, shvae, shnoe, shaev, shaon) shave himself carefully with the razor.

Lillian counted fifty (sheep, sehep, sofep, shepe, shego) sheep before finally falling asleep.

The committee decided to adopt (tight, tihgt, titpt, tigth, tiglk) tight restrictions on labor relations.

The Boy Scout troop helped clean (ocean, ocaen, ocoun, ocena, oceve) ocean shorelines after the oil spill.

Adding some soft (music, muisc, muonc, musci, musno) music created a romantic ambiance in the restaurant.

That presidential candidate has various (ideas, idaes, idous, idesa, ideve) ideas regarding tax reform.

Looking back, I can only recall (sober, soebr, soafr, sobre, sobsa) sober moments from my college experience.

I am getting better at solving (short, shrot, shnet, shotr, shofn) short multiplication problems in my head.

The tape included brief (songs, snogs, scegs, sonsg, sonvp) songs representing all of the work she had done.

After much thought, the fair (judge, jugde, jupte, judeg, judop) judge sentenced the man to 5 years in jail.

The boys chose to install (wagon, waogn, waujn, wagno, wagve) wagon wheels to the under side of the racecar.

Iridium is a rare (metal, meatl, meokl, metla, metko) metal found only in meteors and asteroids.

Consumer Reports gave the car a worse (value, vaule, vaote, valeu, valoi) value rating than the Civic.

The teacher was shocked when the ordinarily quiet (girls, gilrs, gifcs, girsl, girnt) girls disrupted class.

In ideal conditions, the giant ragweed's rough (stems, setms, sohms, stesm, stevn) stems grow up to 15 feet.

I was shocked to learn that my cousin (plays, palys, pokys, plasy, plarg) plays guitar in a local rock band.

Grandma Anderson helped Adam (roast, raost, reust, roats, roaln) roast turkey for the annual family dinner.

Taking just one bite into a sweet (peach, paech, puoch, peahc, peakn) peach reminds me of summertime.

The squire watched the prince (shoot, sohot, sekot, shoto, shoku) shoot arrows in the palace courtyard.

Mario helped the blind (child, chlid, chfod, chidl, chikf) child find her classroom on the first day.

Heidi found the sick (robin, roibn, roodn, robni, robso) robin lying under the maple tree in the backyard.

We heard the guest speaker (teach, taech, toich, teahc, teatv) teach interviewing skills to our class.

To make a budget, one should first list (major, maojr, maegr, majro, majse) major monthly expenses.

The documentary showed an angry (tiger, tiegr, tiopr, tigre, tigso) tiger running after a herd of deer.

I think Bert (loves, loevs, loons, lovse, lovna) loves camping in the Smoky Mountains with his girlfriend.

Go to the dollar store and buy a plastic (broom, borom, bunom, bromo, brova) broom tomorrow when you're out.

The pair of pink (coral, coarl, counl, corla, corke) coral earrings came free with the purchase of a ring.

The dry soil in the west is unable to absorb (large, lagre, lapne, lareg, laroj) large amounts of water.

Each weekend, the boys collect (empty, emtpy, emljy, empyt, empjl) empty bottles and redeem them for money.

Kelly went to vote (early, ealry, eatny, earyl, eargk) early Tuesday morning for her favorite candidate.

Peter believes abortion is wrong whereas (maybe, mabye, mafge, mayeb, mayat) maybe others would disagree.

Many migrant farm workers travel (north, notrh, nodnh, norht, norkl) north during the growing season.

Even in dry wooded areas, many wild (onion, oinon, oecon, onino, onive) onion plants grow profusely.

The new sharp (knife, kinfe, kosfe, knief, kniot) knife allowed Jackie to peel the potatoes in little time.

We should have that firm (chair, chiar, choer, chari, chave) chair reupholstered once we get more money.

I used to pour (lemon, leomn, leasn, lemno, lemce) lemon juice on my apple slices to keep them fresh.

The laws help protect (royal, roayl, roepl, royla, royke) royal families from invasive acts of the media.

The guests heard the bride (speak, spaek, spuok, speka, spele) speak promises of faithfulness to her groom.

Pepperoni, ham, and sausage are typical (meats, maets, mouts, meast, meanf) meats found on pizza.

The smell of warm (bread, braed, bruod, breda, brete) bread filled the bakery in the early morning hours.

The chef hoped that the extra (spice, sipce, sagce, spiec, spiar) spice gave his soup a zesty flavor.

Bill wore the brown (pants, patns, palcs, panst, panvk) pants and orange collared shirt to the 70's party.

The story said that the curious (fairy, fiary, foery, faiyr, faijn) fairy explored the meadow for hours.

The avid protesters opposed (rigid, riigd, riopd, rigdi, rigto) rigid rules about gun control.

The father drew peace from watching his baby (sleep, selep, sofep, slepe, slegi) sleep soundly in the crib.

I saw the security guard (usher, uhser, ufner, ushre, ushno) usher three teenagers out of the concert.

Susan likes to color (paper, paepr, paogr, papre, papno) paper dolls with her nieces and nephews.

To get to the park, turn left at the fourth (house, huose, hease, houes, houar) house after the stoplight.

That machine will print (black, balck, botck, blakc, blatn) black text but can't do anything in color.

Out of fear and respect, the loyal servant (never, neevr, neanr, nevre, nevso) never disobeyed his master.

Charlie got his front (teeth, teteh, telah, teeht, teelk) teeth knocked out the first day of practice.

Meg Ann watched the rain (clean, claen, cloun, clena, cleve) clean sidewalk chalk off of the driveway.

Christopher's tiny (fleas, flaes, fluos, flesa, fleve) fleas performed flawlessly in the miniature circus.

Unlike humans, the female (camel, caeml, caorl, camle, camko) camel remains pregnant for 13 months.

Those persons that commit (fraud, fruad, froed, fradu, frato) fraud repeatedly will eventually be caught.

I think I can smell (bacon, baocn, bausn, bacno, bacse) bacon cooking in the kitchen this morning.

Lee bought the smaller (globe, golbe, gutbe, gloeb, gloat) globe Monday for Tim and gave it to him Friday. 
The corner market rarely (sells, slels, sfols, selsl, selnt) sells cigarettes to people under age.

The children watched the maid (carry, crary, cnory, caryr, cargn) carry cleaning supplies up the stairs.

My college roommate got to judge (polka, pokla, pofta, polak, polet) polka dancing competitions all summer.

With great precision, the careful (nurse, nusre, nunce, nures, nuran) nurse administered the tetanus shot.

After the accident, Seth was left with a slight (flesh, felsh, fofsh, flehs, fletn) flesh wound in his arm.

Using only loose (corks, croks, cneks, corsk, corvt) corks prevents bottles from bursting during fermentation.
Maria and Kyle's rich (uncle, unlce, untce, uncel, uncof) uncle donated a thousand dollars to the charity.

The picky neighbor girls hate (salty, satly, safky, salyt, salgk) salty foods and anything with nuts in it.

Note. The five parafoveal preview conditions (identity baseline, transposed letter-internal, substituted letter-internal, transposed letter-final, and substituted letter-final, respectively) are shown within the parentheses, followed by the target word in boldface. Sentences were normed for both predictability and understandability.

Appendix B

Experimental Sentences and Preview Conditions in Experiment 2

The young but skilled (acrobat, acrboat, acrdeat, acrobta, acrobko) acrobat entertained the audience at the circus.

We got cheaper rates from the smaller (airport, airoprt, airegrt, airpotr, airpohn) airport and were able to save $\$ 300$.

It's very dangerous to combine (alcohol, alchool, alcbaol, alcohlo, alcohte) alcohol with other drugs or risky activities.

I wasn't surprised when the stronger (athlete, athelte, athodte, athleet, athleak) athlete won the wrestling competition.

Peggy rarely went out onto the high (balcony, balocny, balarny, balcoyn, balcogx) balcony because of her fear of heights.

The children put a thick (bandage, banadge, banubge, bandaeg, bandaoy) bandage on the wound until medical help arrived.

The blue and yellow (blanket, blaknet, blafret, blankte, blankba) blanket matched nicely in the new baby's nursery.

Tyler bought the largest (bouquet, bouuqet, bouoget, bouqute, bouqudo) bouquet of flowers he could find for his wife.

Yellowstone is home to the last wild (buffalo, bufaflo, bufeklo, buffaol, buffaut) buffalo herd in the world.

We had the wooden (cabinet, cabniet, cabsaet, cabinte, cabinfu) cabinet custom-made to match the dining room furniture.

Although most spiders (capture, caputre, capalre, captuer, captuom) capture their prey using webs, some hunt their food.

Andy went to the store and bought a suitable (costume, cosutme, cosofme, costuem, costuaw) costume for the disco party.

We finally repaired the torn (curtain, curatin, curudin, curtani, curtaco) curtain and replaced the old carpet, too.

Due to the complications, my primary (dentist, denitst, denebst, dentits, dentidr) dentist referred me to an oral surgeon.

Ron helplessly watched the storm (destroy, desrtoy, desnloy, destryo, destrqe) destroy the house his grandfather built.

My roommates like to party, but they rarely (disturb, disutrb, disabrb, distubr, distukv) disturb me when I'm studying.

Near Australia, there is a healthy (dolphin, dolhpin, doldgin, dolphni, dolphvo) dolphin population in the ocean waters.

For their anniversary, Bert treated Becca to a romantic (evening, eveinng, evearng, evenign, evenipz) evening on the town.

We listened to the salesman (explain, expalin, expekin, explani, explara) explain the differences between the printers.

The city's enormous (factory, facotry, facukry, factoyr, factogn) factory provided jobs for thousands of workers.
Other than the tiny (freckle, frekcle, frehsle, freckel, freckot) freckle above my lip, my sister and I are identical.

The relatively weak (gravity, graivty, graosty, graviyt, gravijf) gravity of the Moon enables astronauts to jump very high.

To make it to the Olympics, the active (gymnast, gymanst, gymuzst, gymnats, gymnabr) gymnast practiced 80 hours a week. Driving on the flat (highway, higwhay, higmday, highwya, highwqu) highway through Kansas all day was quite boring.

After being trapped in the building all day, the female (hostage, hosatge, hosukge, hostaeg, hostaaj) hostage was set free.

Ever since my previous (husband, husabnd, husulnd, husbadn, husbalm) husband cheated on me, I'm slow to trust people.

Many high school teachers (inspire, insipre, insaqre, inspier, inspioc) inspire their students to think creatively.

Jim thought that his sister needed some formal (jewelry, jewlery, jewtory, jewelyr, jewelpz) jewelry for her wedding day.

Molly kept the secret (journal, jounral, jouvzal, journla, journbe) journal hidden underneath her mattress.

My mother loudly gasped when she saw the dirty (kitchen, kithcen, kitbwen, kitchne, kitchco) kitchen in my apartment.

The old rural (library, libarry, libenry, librayr, libragv) library used a card catalogue instead of an online database.

Little Johnny's unusual (machine, macihne, macabne, machien, machiam) machine at the science fair could butter toast.

Those reading glasses (magnify, maginfy, magusfy, magniyf, magniph) magnify print, making it easier to discriminate text.

Women with blue eyes should use brown (mascara, masacra, masorra, mascaar, mascaow) mascara to accentuate their lashes.

The SAT and ACT mostly (measure, meausre, meaoxre, measuer, measuas) measure how good you are at taking the test.

After I have a brief (meeting, meeitng, meealng, meetign, meetiqm) meeting with my advisor, we can go out to lunch.

In filing taxes each year, a frequent (mistake, misatke, misebke, mistaek, mistaof) mistake is failing to sign the forms.

I had a very busy (morning, morinng, moresng, mornign, morniyc) morning yesterday but managed to get a lot of work done.

The child spread (mustard, musatrd, musukrd, mustadr, mustatz) mustard onto the bread before adding the turkey and cheese.

Anthony prepared a bowl of warm (oatmeal, oatemal, oatowal, oatmela, oatmebu) oatmeal after coming in from the cold. 
Do you think that Roger's firm (opinion, opiinon, opiacon, opinino, opinira) opinion is backed by good evidence?

They sold the estate with the lovely (orchard, orcahrd, orcofrd, orchadr, orchakv) orchard full of apple and pear trees.

The chef ran to the store to purchase (paprika, papirka, papocka, papriak, papriot) paprika for the Hungarian goulash.

Anita bought the valuable (perfume, perufme, perahme, perfuem, perfuaw) perfume from a small shop in downtown Paris.

I confess that I am a terrible (pianist, piainst, piaocst, pianits, pianiln) pianist and can't sing on key either.

Does that new business (pollute, polulte, polebte, polluet, polluof) pollute the water, thereby endangering our health?

The manager heard the engineer (propose, proopse, prougse, propoes, propoam) propose an excellent idea for the company.

While the audience applauded, the proud (quartet, quatret, quadxet, quartte, quartfu) quartet gave their final bow.

Sue quickly took a picture of the distant (rainbow, raibnow, raidrow, rainbwo, rainbra) rainbow before it faded away.

We were shocked when we heard the reporter (release, relaese, relouse, releaes, releaoc) release unauthorized information.

Jill showed her huge (respect, resepct, resajct, respetc, respebs) respect for missionaries by donating to the charity.

The registration fee included a daily (seminar, semniar, semzoar, seminra, seminzo) seminar on how to manage your money.
The president gave the willing (soldier, solider, soluber, soldire, soldimo) soldier a medal for his bravery.

Don't forget to pick up some fresh (spinach, spianch, spierch, spinahc, spinadn) spinach for our vegetarian lasagna.

Most experienced runners (stretch, strtech, strloch, strethc, stretbr) stretch both before and after a race.

We were excited to hear the travel agent (suggest, sugegst, sugoqst, suggets, suggelz) suggest exotic honeymoon locations.

In 1925, a massive (tornado, torando, toromdo, tornaod, tornaeb) tornado killed almost 700 people in the Midwest.

When I saw the coach (torture, torutre, torehre, tortuer, tortuom) torture his players by running laps, my own legs hurt.

When Katie got sick, she took her regular (vitamin, vitmain, vitwuin, vitamni, vitamca) vitamin along with her medication.

Perhaps the most famous (volcano, volacno, volevno, volcaon, volcauc) volcano in the world is Mount Vesuvius in Italy.

Note. The five parafoveal preview conditions (identity baseline, transposed letter-internal, substituted letter-internal, transposed letter-final, and substituted letter-final, respectively) are shown within the parentheses, followed by the target word in boldface. Sentences were normed for both predictability and understandability.

Appendix C

Experimental Sentences and Preview Conditions in Experiment 3

The young but skilled (acrobat, carobat, nerobat, acroult, acrobta, acroblo) acrobat entertained the audience at the circus.

We got cheaper rates from the smaller (airport, iarport, ourport, airpset, airpotr, airpola) airport and were able to save $\$ 300$.

It's very dangerous to combine (alcohol, lacohol, hecohol, alcoekl, alcohlo, alcohta) alcohol with other drugs or risky activities.

It was difficult for the nervous (apostle, paostle, geostle, aposdhe, apostel, apostad) apostle to trust what he had seen.

I wasn't surprised when the stronger (athlete, tahlete, lihlete, athlfae, athleet, athleil) athlete won the wrestling competition.

Kaitlin was sure it was the largest (avocado, vaocado, weocado, avocfeo, avocaod, avocaif) avocado she had ever seen.

Peggy rarely went out onto the high (balcony, ablcony, otlcony, balcsay, balcoyn, balcogs) balcony because of her fear of heights. The children put a thick (bandage, abndage, otndage, bandpie, bandaeg, bandaup) bandage on the wound until medical help arrived.

The tea came with an excellent (biscuit, ibscuit, efscuit, biscoet, biscuti, biscula) biscuit that one ate with jam.

The blue and yellow (blanket, lbanket, tfanket, blanoht, blankte, blankdi) blanket matched nicely in the new baby's nursery.

Tyler bought the largest (bouquet, obuquet, uduquet, bouqoat, bouqute, bouqudi) bouquet of flowers he could find for his wife. Yellowstone is home to the last wild (buffalo, ubffalo, odffalo, buffteo, buffaol, buffait) buffalo herd in the world.

We had the wooden (cabinet, acbinet, erbinet, cabiast, cabinte, cabindi) cabinet custom-made to match the dining room furniture.
Although most spiders (capture, acpture, erpture, captvie, captuer, captuac) capture their prey using webs, some hunt their food.

Dave was determined to fix the crazy (chimney, hcimney, bvimney, chimasy, chimnye, chimnju) chimney that was falling down. Any change in the delicate (climate, lcimate, hsimate, climloe, climaet, climail) climate could cause a great deal of harm.

The whole thing began with a stupid (contest, ocntest, izntest, contrat, contets, contebr) contest between two friends.

Andy went to the store and bought a suitable (costume, ocstume, izstume, costwoe, costuem, costuir) costume for the disco party. Dr. Smith discovered a unique (cricket, rcicket, smicket, cricoht, crickte, crickdi) cricket before unknown to science.

The woman carried a wonderful (crystal, rcystal, smystal, crysedl, crystla, crysthe) crystal in her jacket pocket.

We finally repaired the torn (curtain, ucrtain, ovrtain, curtoun, curtani, curtara) curtain and replaced the old carpet, too.

On the couch a yellow (cushion, ucshion, ovshion, cushaun, cushino, cushisa) cushion had replaced an old one.

Due to the complications, my primary (dentist, edntist, ilntist, dentvet, dentits, dentibr) dentist referred me to an oral surgeon. Ron helplessly watched the storm (destroy, edstroy, ilstroy, destuny, destryo, destrje) destroy the house his grandfather built. Walter bought a large (diamond, idamond, utamond, diamsad, diamodn, diamohw) diamond ring for his wife of twenty years. My roommates like to party, but they rarely (disturb, idsturb, utsturb, distvib, distubr, distuts) disturb me when I'm studying. Becky's parents endured an uneasy (divorce, idvorce, utvorce, divosme, divorec, divorom) divorce but remained close afterward. 
Near Australia, there is a healthy (dolphin, odlphin, iflphin, dolpukn, dolphni, dolphra) dolphin population in the ocean waters. That night a perfect (eclipse, celipse, malipse, eclirye, eclipes, eclipur) eclipse was visible from the yard.

The scientist made sure to later (elevate, leevate, taevate, elevloe, elevaet, elevail) elevate the hormone level in the animal.

Allie shocked everyone when she had a rare (episode, peisode, gaisode, episbie, episoed, episoil) episode of intense anger.

For their anniversary, Bert treated Becca to a romantic (evening, veening, siening, evenrag, evenign, eveniys) evening on the town. We listened to the salesman (explain, xeplain, zoplain, exploun, explani, explara) explain the differences between the printers.

The city's enormous (factory, afctory, ebctory, factsey, factoyr, factogm) factory provided jobs for thousands of workers.

It had changed somewhat, but the popular (formula, ofrmula, ebrmula, formfoa, formual, formuet) formula for songs was still used.

Other than the tiny (freckle, rfeckle, xteckle, frecfte, freckel, freckad) freckle above my lip, my sister and I are identical.

Although the place was old, it had a reliable (furnace, ufrnace, ikrnace, furnmee, furnaec, furnaom) furnace that always worked. The relatively weak (gravity, rgavity, cyavity, gravloy, graviyt, gravigh) gravity of the Moon enables astronauts to jump very high.

To make it to the Olympics, the active (gymnast, ygmnast, pjmnast, gymncit, gymnats, gymnabr) gymnast practiced 80 hours a week.

Together the girls created a sweet (harmony, ahrmony, ikrmony, harmsay, harmoyn, harmogs) harmony for the enjoyment of their guests.

The prices set for the original (harvest, ahrvest, ikrvest, harvrat, harvets, harvebr) harvest were maintained for the next one.

Driving on the flat (highway, ihghway, ukghway, highoxy, highwya, highwjo) highway through Kansas all day was quite boring. After being trapped in the building all day, the female (hostage, ohstage, ukstage, hostpie, hostaeg, hostaup) hostage was set free. Ever since my previous (husband, uhsband, eksband, husbmed, husbadn, husbahw) husband cheated on me, I'm slow to trust people.

Many high school teachers (inspire, nispire, caspire, inspnae, inspier, inspiac) inspire their students to think creatively.

Jim thought that his sister needed some formal (jewelry, ejwelry, oqwelry, jewenfy, jewelyr, jewelgm) jewelry for her wedding day. Molly kept the secret (journal, ojurnal, uyurnal, jouresl, journla, journte) journal hidden underneath her mattress.

My mother loudly gasped when she saw the dirty (kitchen, iktchen, ahtchen, kitcikn, kitchne, kitchro) kitchen in my apartment.

The only light came from a pink (lantern, alntern, etntern, lantman, lantenr, lantexc) lantern that hung from the deck.

There was a marble (leopard, elopard, atopard, leopned, leopadr, leopals) leopard in the foyer of the grand mansion.

The old rural (library, ilbrary, edbrary, librney, librayr, libragm) library used a card catalogue instead of an online database.

Little Johnny's unusual (machine, amchine, oschine, machrae, machien, machias) machine at the science fair could butter toast. Those reading glasses (magnify, amgnify, osgnify, magnkey, magniyf, magnigt) magnify print, making it easier to discriminate text.

Women with blue eyes should use brown (mascara, amscara, ecscara, mascnea, mascaar, mascaen) mascara to accentuate their lashes.

The SAT and ACT mostly (measure, emasure, irasure, measvie, measuer, measuac) measure how good you are at taking the test. After I have a brief (meeting, emeting, ireting, meetrag, meetign, meetiys) meeting with my advisor, we can go out to lunch.

In filing taxes each year, a frequent (mistake, imstake, ocstake, misthue, mistaek, mistaoh) mistake is failing to sign the forms.

I had a very busy (morning, omrning, ecrning, mornrag, mornign, morniys) morning yesterday but managed to get a lot of work done.

The child spread (mustard, umstard, irstard, mustned, mustadr, mustals) mustard onto the bread before adding the turkey and cheese.

They vowed to destroy the guerilla (network, entwork, ictwork, netwsek, netwokr, netwotz) network before another incident occurred.

Anthony prepared a bowl of warm (oatmeal, aotmeal, iutmeal, oatmiul, oatmela, oatmete) oatmeal after coming in from the cold. Do you think that Roger's firm (opinion, poinion, gainion, opinaun, opinino, opinisa) opinion is backed by good evidence?

They sold the estate with the lovely (orchard, rochard, sichard, orchned, orchadr, orchals) orchard full of apple and pear trees. The chef ran to the store to purchase (paprika, apprika, igprika, paprfua, papriak, papriud) paprika for the Hungarian goulash.

The man stood in the center of the empty (pasture, apsture, igsture, pastvie, pastuer, pastuac) pasture and contemplated the sky.

Anita bought the valuable (perfume, eprfume, ogrfume, perfwoe, perfuem, perfuos) perfume from a small shop in downtown Paris. I confess that I am a terrible (pianist, ipanist, eganist, pianvet, pianits, pianibr) pianist and can't sing on key either.

Does that new business (pollute, opllute, agllute, pollfie, polluet, polluil) pollute the water, thereby endangering our health?

Hannah made an enormous (promise, rpomise, cyomise, promrae, promies, promion) promise to her sister.

The manager heard the engineer (propose, rpopose, cyopose, propcue, propoes, propour) propose an excellent idea for the company.

They discovered that the current (protein, rpotein, cyotein, protoun, proteni, protera) protein was larger than they had thought. Overall, the winner was the prize (pumpkin, upmpkin, egmpkin, pumpahn, pumpkni, pumpkra) pumpkin that weighed two hundred pounds.

While the audience applauded, the proud (quartet, uqartet, iyartet, quarilt, quartte, quartdi) quartet gave their final bow.

Sue quickly took a picture of the distant (rainbow, arinbow, eninbow, rainefw, rainbwo, rainbmu) rainbow before it faded away.

We were shocked when we heard the reporter (release, erlease, iclease, relenoe, releaes, releaic) release unauthorized information. Jill showed her huge (respect, erspect, onspect, respnet, respetc, respeks) respect for missionaries by donating to the charity.

The registration fee included a daily (seminar, esminar, acminar, semiesr, seminra, seminco) seminar on how to manage your money.

The children were fed by the tiny (servant, esrvant, acrvant, servmet, servatn, servafs) servant when their mother was ill.

Her statement was met with a solid (silence, islence, enlence, silerze, silenec, silenom) silence from the crowd. 
The president gave the willing (soldier, osldier, amldier, soldoar, soldire, soldico) soldier a medal for his bravery.

It was the curious (soprano, osprano, amprano, soprmeo, sopraon, soprais) soprano who tried it first.

Don't forget to pick up some fresh (spinach, psinach, gninach, spinmeh, spinahc, spinabv) spinach for our vegetarian lasagna.

They all went to the temporary (stadium, tsadium, bradium, stadoam, stadimu, stadiwo) stadium for the event that day.

Paul's dog had the biggest (stomach, tsomach, bromach, stomneh, stomahc, stomabv) stomach I'd ever seen.

Most experienced runners (stretch, tsretch, lmretch, strerdh, strethc, stretbv) stretch both before and after a race.

The stairs offered a potential (stumble, tsumble, brumble, stumtfe, stumbel, stumbad) stumble that would be very dangerous.

We were excited to hear the travel agent (suggest, usggest, inggest, suggrat, suggets, suggebr) suggest exotic honeymoon locations.

The teenage boy's random (suicide, usicide, inicide, suicfae, suicied, suiciol) suicide created a stir in the town.

The door opened and a European (surgeon, usrgeon, inrgeon, surgiun, surgeno, surgesa) surgeon entered the woman's room.

They decided to further (suspend, usspend, inspend, susprad, suspedn, suspehw) suspend his privileges as punishment.

Another option was spiritual (therapy, hterapy, lderapy, thergey, therayp, theraqj) therapy, if it was wanted.

In 1925, a massive (tornado, otrnado, abrnado, tornfeo, tornaod, tornaif) tornado killed almost 700 people in the Midwest.

A new project, the remote (torpedo, otrpedo, abrpedo, torplao, torpeod, torpeif) torpedo, was a great success.
When I saw the coach (torture, otrture, abrture, tortvie, tortuer, tortuac) torture his players by running laps, my own legs hurt.

According to the policeman, the drunk (tourist, oturist, aburist, tourvet, tourits, touribr) tourist had no idea where he was.

Of the recent years, the atomic (tragedy, rtagedy, ckagedy, traglay, trageyd, tragept) tragedy was best remembered.

Of her children, the mother loved the musical (triplet, rtiplet, ckiplet, tripadt, triplte, tripldi) triplet the most.

From the drawer a familiar (utensil, tuensil, biensil, utenorl, utensli, utensta) utensil had been removed.

The book suggested minimal (vinegar, ivnegar, ocnegar, vineopr, vinegra, vinegco) vinegar be used in the dish.

When Katie got sick, she took her regular (vitamin, ivtamin, octamin, vitaosn, vitamni, vitamra) vitamin along with her medication.

Perhaps the most famous (volcano, ovlcano, uclcano, volcmeo, volcaon, volcais) volcano in the world is Mount Vesuvius in Italy.

The woman saw an obvious (wrinkle, rwinkle, nminkle, wrinfte, wrinkel, wrinkad) wrinkle on her face.

Note. The six parafoveal preview conditions (identity baseline, transposed letter-initial, substituted letter-initial, substituted letter-internal, transposed letter-final, and substituted letter-final, respectively) are shown within the parentheses, followed by the target word in boldface. Sentences were normed for both predictability and understandability.

Received May 29, 2005

Revision received August 7, 2006

Accepted August 8, 2006

\section{E-Mail Notification of Your Latest Issue Online!}

Would you like to know when the next issue of your favorite APA journal will be available online? This service is now available to you. Sign up at http://watson.apa.org/ notify/and you will be notified by e-mail when issues of interest to you become available! 
Reproduced with permission of the copyright owner. Further reproduction prohibited without permission. 